\title{
LA CONSTITUCIÓN Y SU ESTUDIO. UN EPISODIO EN LA FORJA DEL DERECHO CONSTITUCIONAL EUROPEO: MÉTODO JURÍDICO Y RĖGIMEN POLÍTICO EN LA LLAMADA TEORÍA CONSTITUCIONAL DE WEIMAR (Y II $)^{1}$
}

\author{
JAVIER RUIPÉREZ ALAMILLO \\ Catedrático de Derecho Constitucional \\ Universidad de La Coruña
}

SUMARIO

I. Sobre la oportunidad de esta Jornada.

II. ¿Por qué mirar al debate de los constitucionalistas del período entre guerras?

III. La incapacidad del iuspublicismo preweimariano para construir una Teoría de la Constitución como Derecho de la Libertad y de la Democracia.

IV. La pervivencia del positivismo jurídico formalista en el período entre guerras y sus consecuencias.

V. La contribución de la llamada "Teoría Constitucional de Weimar" a la consolidación del Derecho Constitucional europeo:

1 Este trabajo se presentó a las Jornadas sobre Orientación y Método del Derecho Constitucional organizadas por la revista Teoría y Realidad Constitucional el 16 de noviembre de 2007. La primera parte del mismo (apartados I a IV) se publicó en el número 21 de esta revista. 


\section{LA CONTRIBUCIÓN DE LA LLAMADA «TEORÍA DE LA CONSTITUCIÓN DE WEIMAR" A LA CONSOLIDACIÓN DEL DERECHO CONSTITUCIONAL EUROPEO}

\section{A) Miserias POlíticas y GRANDEZa JURÍDiCA DEL PERÍODO ENTRE GUERRAS}

Nadie puede, al menos cabalmente, negar que desde el punto de vista político-social, el período entre guerras fue una etapa en exceso convulsa, compleja y difícil. Tanto es así que en modo alguno resultaría exagerado afirmar que la situación que se creaba con el fin de la Primera Guerra Mundial, y que definiría la vida política y social europea de las décadas de 1920, 1930 y los primeros años de 1940, resultó dramática y desastrosa desde una óptica democrática. La razón es fácilmente comprensible.

La situación de crisis económica que arrastraban los Estados europeos desde los últimos años del siglo xIx, había conocido un cierto alivio como consecuencia de la Gran Guerra. En efecto, las exigencias derivadas de la necesidad de atender adecuadamente el conflicto bélico se tradujo, como podía ser de otro modo, en un incremento de la producción, el empleo y, consecuentemente, de la riqueza, debido, en buena medida, al aumento de la demanda generado por los Gobiernos contendientes. Incremento de la producción y del empleo del que se beneficiaron, en términos sociales, no sólo los Estados beligerantes, sino también aquellos otros que, bien fuera como resultado de un maduro examen de las conveniencias nacionales y/o por convicciones morales, bien fuese, —como sucedió, por ejemplo, y al decir de Azaña ${ }^{2}$, con la España de la Restauración.-, porque se vieron obligados a ello por su propia incapacidad militar y técnica, optaron por la neutralidad.

Acabado el conflicto bélico, la economía, singularmente la de los países contendientes, y de manera muy especial, la de Italia y Alemania, no sólo volvería a una situación crítica, sino que, además, empeoraría respecto de la situación anterior a la Primera Guerra Mundial. La falta de demanda por parte del sector público habría de generar una más que sobresaliente disminución en la producción que, como es, por lo demás, obvio, provocaría una gran y honda preocupación, y desconfianza, en los titulares del capital respecto de quienes ocupaban el poder político. Por su parte, la disminución de la producción se tradujo en una creciente falta de empleo que, en última instancia, afectaba tanto a las clases medias, propietarias o no, como al proletariado urbano e industrial.

No hace falta ser un especialista en las Ciencias Económicas, para poder afirmar que, con carácter general, los gobernantes del momento se vieron incapacitados para encontrar una solución eficaz y adecuada a la crisis económica. Esto sucedió, en efecto, y sin que deje de ser lógico, en aquellos países

2 Cfr. M. Azaña, "Los motivos de la germanofilia. Texto mecanografiado del discurso pronunciado en el Ateneo de Madrid (Sección de Ciencias Históricas), el 25 de mayo de 1917, al discutirse la actitud de España ante la guerra", en M. AzAÑa, Discursos políticos, cit., págs. 43-62. 
cuyos ordenamientos jurídicos respondían, todavía en el período entre guerras, a los esquemas políticos del liberalismo. Aunque, como ha escrito el Maestro De $\mathrm{Vega}^{3}$, lejos de ser correcta aquella crítica ideológica que concebía al Estado liberal como un simple "vigilante nocturno" (Lassalle) que, finalmente, se mostraba como una organización inoperante y vacía, no deja de ser, sin embargo, cierto que, erigido éste sobre la separación radical y absoluta entre el Estado y la sociedad, y concibiendo la economía como uno de los contenidos centrales de esa esfera de libertad individual absoluta en la que, por pertenecer a la sociedad, no debía interferir el Estado-aparato, los gobernantes, ya fueran liberales, demócratas o socialistas ${ }^{4}$, carecen de medios jurídicos adecuados para conducir y controlar el proceso productivo y, de este modo, enfrentarse a la crisis económica.

Esta misma incapacidad para solventar la crisis se verificó también en aquellos otros Estados que, finalizada la Gran Guerra, procedieron a la aprobación de unos nuevos Códigos Fundamentales que respondían ya a los presupuestos del Estado Constitucional democrático y social. El supuesto de la Alemania de Weimar es, a este respecto, paradigmático.

Aprobado el Texto de 1919 como el fruto de un cierto consenso entre liberales y conservadores, por un lado, y progresistas, por otro, y habiendo en la Asamblea Constituyente una fuerte presencia del socialismo marxista, aparecerá, como escribe Hermann Heller, «en esa Constitución una importante sección, "De la Economía", que no es dado encontrar en ninguna constitución precedente, y [...que] contiene, [...], una serie de proposiciones programáticas sin fuerza jurídica de obligar. Pero al propio tiempo contiene la cuestión decisiva de la polémica, tan embrollada, tan ardua, entre la concepción económica individualista (capitalista) de la burguesía, y la reforma socialista de la economía enarbolada y a la que aspira el proletariado. [...]. El espíritu de esa polémica - a tenor de la Constitución- no es el de la lucha de clases marxiana o el de la dictadura, sino el de la conciliación, y en lo posible, del acuerdo recíproco orientados al fin de una más justa distribución de recur$\operatorname{sos}{ }^{5}$. Se sentaban, de este modo, las bases, que se generalizarían con el fin de la Segunda Guerra Mundial, para que el sector público pudiera intervenir en el proceso económico, ya mediante la mera planificación del proceso productivo, ya como posible titular de los medios de producción. Ahora bien, es lo cierto que, pese a contar con mecanismos constitucionales que autorizaban el control y la conducción de la vida económica, las medidas adoptadas al respecto por los Gobiernos socialistas de la República de Weimar devinieron inoperantes e insuficientes ante la magnitud de la crisis y, al mismo tiempo, de la escasez de recursos económicos con los que contaban, y que en buena medida se debían a la herencia del Estado liberal.

3 Cfr. P. De Vega, "Mundialización y Derecho Constitucional:...”, cit., pág. 45.

4 Para la ponderada comprensión de la contraposición entre liberales, demócratas y socialistas, cfr., por todos, H. Heller, Las ideas..., cit., págs. 14, 71-72 y 78-80.

5 H. Heller, "El Derecho Constitucional de la República de Weimar. Derechos y deberes fundamentales. Sección V: De la Economía”, en el vol. Escritos políticos, cit., págs. 270-271. 
De nada valían, en tales circunstancias, las enfáticas declaraciones realizadas por el Constituyente de Weimar en el sentido de, por ejemplo, asegurar la protección del Estado a las clases medias (art. 164 Const. alemana de 1919), o la de dispensar una especial atención al trabajo (art. 157) ${ }^{6}$. Una y otra quedaban, de manera inevitable, condenadas a disolverse en el campo de las buenas intenciones, y frente a la imposibilidad, impuesta por la propia realidad, de atajar la crisis económica.

No podemos, en la medida en que ello nos obligaría a abordar una serie de estudios que transcienden los límites objetivos de este trabajo, detenernos en un análisis exhaustivo y en una crítica técnico-económica pormenorizada de esta circunstancia. Lo que realmente nos interesa aquí, es destacar los efectos políticos que aquélla produjo. Y es que, de manera inevitable, la situación de crisis económica por la que atravesaba Europa generó una serie de consecuencias políticas muy concretas. Consecuencias políticas que, a nadie puede ocultársele, no pudieron ser más peligrosas para la Democracia, y, con ello, más perniciosas y nefastas para el desarrollo y consolidación de la manifestación estructural del Estado Constitucional cuya vida se iniciaba entonces.

De manera que no puede sino considerarse paradójica, la anterior circunstancia se vería agravada con el triunfo electoral de las fuerzas políticas progresistas. Lo que, creemos, no resulta, empero, muy difícil de comprender. Es menester tomar en consideración, a este respecto, que el acceso de éstas a las posiciones mayoritarias y, en consecuencia, a la de partidos encargados de formar Gobierno, acabó produciendo un progresivo desapego hacia el Estado Constitucional por parte de la alta burguesía propietaria. Aunque de modo absolutamente injustificado, el gran capital, hondamente impresionado por lo acaecido en la Unión Soviética, miraría con un gran recelo las medidas económicas y sociales adoptadas por demócratas, demócratas radicales y socialistas, las cuales eran interpretadas por los primeros, no como medidas con las que superar la crisis económica, a la par que a dar cumplimiento a esa lucha por la igualdad que, como había afirmado ya Rousseau ${ }^{7}$, se convertía en el objetivo último de la organización estatal democrática, sino, muy al contrario, como instrumentos de los que se servía el proletariado para despojarles de aquella situación de privilegio, económico y social, de la que el gran capital gozaba ya desde los últimos tiempos del Estado absoluto. De cualquier forma, ese temor, unido a la pérdida efectiva del poder político, determinó que, con carácter general, los capitalistas afrontasen la situación de crisis económica apostando, en el marco de la confrontación partidista, no sólo por las fuerzas políticas más radicalmente antidemócratas, sino, incluso, por las antiliberales.

6 Cfr., sobre ambos, H. Heller, "El Derecho Constitucional de la República de Weimar...", cit., págs. 278 y 275 , respectivamente.

7 Cfr. J.-J. Rousseau, "Proyecto de Constitución para Córcega" (1765), en el vol. Proyecto de Constitución para Córcega. Consideraciones sobre el gobierno de Polonia y su proyecto de reforma, Madrid, 1988, pág. 13. 
Algo parecido sucedería entre el proletariado. En efecto, $-\mathrm{y}$, por ejemplo, como, ya en el exilio, observó el Presidente Azaña ${ }^{8}$ respecto de la República democrática española-, el relativamente fácil y extenso triunfo de demócratas, demócratas radicales y socialistas, hizo nacer en la pequeña burguesía y, sobre todo, en el proletariado unas extraordinarias expectativas en cuanto a su situación política, económica y social. Expectativas que se verían defraudadas por la práctica política de las fuerzas progresistas en el Gobierno. Al no entender los pequeño-burgueses y proletarios que esta circunstancia, de manera fundamental, se debía no al propio ideario y proyecto programático de demócratas y socialistas, sino a las limitaciones que a éstos les imponía la propia realidad, fueron no pocos los que reaccionaron en contra de las organizaciones partidistas que, según entendían, estaban traicionándoles. Y no sólo contra éstas. También lo harían contra el propio sistema en su conjunto al que discutían su legitimidad. En lo que, pequeña burguesía y proletariado, encontraban amparo en el discurso de las fuerzas antisistema.

Heller, — sin disputa, el más inteligente, lúcido, válido, capaz y coherente de cuantos se dedicaron al estudio del Estado, la Política y el Derecho en ese tiempo-, se referiría a esta circunstancia. Aunque la cita sea larga, no nos resistimos a transcribir su atinada denuncia. Dirá, en este sentido, el joven constitucionalista, y militante de las juventudes socialistas, lo siguiente: “¿Dónde estaban entonces sus críticos actuales, cuando fueron puestas las bases de esta Constitución, cuando hombres conscientes de la responsabilidad se opusieron al caos con suficiente tesón, bajo peligro de muerte, mientras los jefes del antiguo régimen, que eran [...] culpables de ese caos, o bien huían al extranjero o bien, [...], pedían a voces la Asamblea Nacional constituyente y el techo protector de la democracia? [...] Y cuán fácil es hoy, cuando la república democrático-parlamentaria está implantada, criticar de raíz esa república bajo la protección de sus garantías constitucionales de libertad. [...] Más precisamente esta estructura de nuestra Constitución irrita a nuestros románticos estético-heroicos de la revolución de izquierda y de derecha. Ellos la califican de compromiso corrupto e informal entre el Estado monárquico-liberal de derecho y la democracia político-social. Puesto que unos y otros aspiran a una dictadura, [...], consideran, en curiosa coincidencia, la división de poderes y los derechos fundamentales de la Constitución como prejuicios supervivientes de un Estado burgués de derecho. Su ideal es la violencia incontrolada que puede influir desmedida pero por eso también arbitrariamente en el ciudadano que no está ligada a ley alguna en los tribunales y la administración, y que [...] quiere prescribir al ciudadano lo que a éste se le permite pensar, decir, escribir y leer. Ellos afirman que la división de poderes y los derechos fundamentales son un impedimento para la imposición violenta y radical de su nuevo ideal de forma política" .

8 Cfr. M. AzAÑ̃a, "Causas de la guerra en España”, en el vol. M. Azaña, Causas de la guerra de España, cit., págs. 22-23.

9 H. Heller, "Libertad y forma en la Constitución del Imperio" (1929/1930), en el vol. El sentido de la política y otros ensayos, cit., págs. 64-65. 
La situación que se iba generando, no podía ser, en verdad, más dramática y peligrosa para el Estado Constitucional. Ésta, de cualquier modo, no hace más que confirmar las observaciones que, en su día, había realizado Karl Mannheim ${ }^{10}$ sobre las causas que acaban poniendo en serio peligro, cuando no destruyendo, el sistema democrático. Esto es, que si las soluciones adoptadas en el ámbito jurídico-político abrían unas expectativas que, a la postre, conducían a los ciudadanos a adoptar una actitud de conformismo, es lo cierto que la incapacidad demostrada por los gobernantes para solucionar los problemas sociales y económicos de la sociedad, determinó que el individuo quedase insatisfecho en sus necesidades personales y, por ello mismo, sumido en la más absoluto y profunda de las frustraciones. Lo que, en la medida en que es incapaz de localizar racionalmente la fuente de su frustración, acaba por llevarle a colocarse frente al sistema democrático en su conjunto, y a orientarse hacia los movimientos antisistema. De estos últimos, los más favorecidos serían aquéllos que contaban con una mejor y más sólida organización, o una más efectiva propaganda, para afrontar la lucha política. Nos referimos, claro está, a lo que en aquel momento se llamó "bolcheviquismo" y el "fascismo", caracterizados y, pese a las grandes diferencias que existen entre ellos $^{11}$, equiparados por su oposición a la democracia parlamentaria.

Esto fue, justamente, lo que sucedió en Italia y Alemania. De nada sirvieron las advertencias que, por ejemplo, había realizado a este respecto Heller sobre los peligros que comportaban las fuerzas antisistema, en el sentido de que «En la situación actual de Alemania la dictadura bolchevique — [...] — significaría la lucha desenfrenada y sin regla, el caos de la cultura; pero la dictadura fascista supondría la supresión violenta de las posibilidades de futuro, y su forma rígida debería ser pronto hecha añicos por una explosión " ${ }^{12}$. Los descontentos, insatisfechos y frustrados en sus necesidades sociales y económicas por la nueva democracia parlamentaria, se inclinarían, de manera irremediable y fatal, hacia esas organizaciones antisistema. Particularmente, hacia el fascismo, en Italia, y el nacional-socialismo, en Alemania.

Porque esto es así, fácilmente se comprende el por qué Sabine ha podido afirmar que tanto uno como otro partido "fueron crecimientos degenerados, productos de la desmoralización de la primera Guerra Mundial; sus dirigentes fueron demagogos y, a juzgar por sus realizaciones, su desarrollo fue simplemente destructivo. Sus llamadas filosofías eran mosaicos de viejos prejuicios, reunidos sin tener en cuenta la verdad ni la coherencia, para apelar no a propósitos comunes, sino a miedos y odios comunes. [...]. Al mismo tiempo, el fascismo y el nacionalsocialismo fueron auténticos movimientos populares que, momentáneamente, despertaron una lealtad fanática en miles de alemanes e italianos y hasta sus dirigentes máximos, obviamente cínicos, se enga-

10 Cfr. K. Mannheim, Man and Society in an Age of Reconstruction, Londres, 1940, págs. 53-67.

11 Sobre las diferencias entre el comunismo, por un lado, y el fascismo y nacional-socialismo, por otro, cfr., por todos, G. SABINE, Historia..., cit., págs. 657 y ss.

12 H. Heller, "Libertad y forma...”, cit., pág. 63. 
ñaron a sí mismos casi en la misma medida en que engañaron a los demás" ${ }^{13}$. $\mathrm{Y}$ es que, en efecto, fue la frustración general, el descontento con el sistema $y$, finalmente, la existencia de unos odios comunes las que determinaron el espectacular crecimiento del Partido Nacional Fascista y Partido Nacional Socialista ${ }^{14}$.

A ello contribuyó, en manera decisiva, y de modo incuestionable, la ya aludida ausencia de un ideario claro, de un discurso programático concreto y su evidente y consustancial oportunismo. Piénsese, en este sentido, que tal circunstancia permitía, por ejemplo, a Mussolini presentar al fascismo como un movimiento político en el que todos, cualquiera que fuese su situación económica y social e, incluso, su posición política, tendrían cabida y acomodo, con la única condición de que fuesen italianos. A tal fin responden, en efecto, las palabras que el líder fascista había publicado en "El Pueblo de Italia", según las cuales "Nosotros nos permitimos el lujo de ser aristocrático y democráticos, conservadores y progresistas, reaccionarios y revolucionarios, legalistas e ilegalistas según las circunstancias de tiempo, de lugar, de ambiente en las que nos vemos obligados a vivir y a obrar ${ }^{15}$.

Movidos por la existencia de frustraciones, descontentos y odios comunes, y engañados por la aparente amplitud del movimiento, irían progresivamente adhiriéndose a los totalitarismos fascistas miembros de las distintas clases sociales, las cuales, en realidad, se encontraban inmersos en un más que notable conflicto en cuanto que, unos y otros, tenían unos intereses diversos, contrapuestos y, en cierta medida, irreconciliables. Los primeros en hacerlo, sería una buena parte de unas clases medias persuadidas, en todo caso, de que toda aquella palabrería revolucionaria de corte soreliano, con la que los fascistas, presentándose como los grandes paladines de las reivindicaciones de la clase obrera, trataban de desbancar (destruir) a los partidos del socialismo democrático ${ }^{16}$, no eran más que una pura retórica demagógica. Después lo harían los miembros del gran capital industrial, financiero y agrario, quienes verían en el fascismo su aliado natural frente al avance de los socialistas y, sobre todo, de los comunistas. Finalmente, se incorporaría un importante sector del proletariado, tanto del industrial y urbano como del agrario y rural, que, defraudados y decepcionados con la acción gubernamental de demócratas y socialistas, incrédulos ante las propuestas revolucionarias de las secciones sin-

13 G. SABINE, Historia..., cit., pág. 632. En relaciónn con esa "lealtad fanática", es menester advertir, con Pedro De Vega, que en el supuesto de todos los movimientos que genéricamente se engloban bajo el término de "fascismo", ésta no sólo era, como dice Sabine, momentánea, sino también más aparente que real. De ello eran bien conscientes los propios "jefes" fascistas. El caso del Duce es, en este sentido, bien elocuente. En efecto, Mussolini era plenamente consciente de que, en el fondo, esas masas que le aclamaban no le querían, sino que le temían. Convencimiento éste al que contribuían los sucesivos atentados que aquél sufrió. Cfr. P. De VeGA, "Mussolini:...", cit., pág. 264.

14 Aunque referido exclusivamente al supuesto italiano, cfr., en este sentido, y por todos, P. De Vega, "Mussolini:...", cit., pág. 252.

15 Citado por P. De VeGA, "Mussolini:...", cit., pág. 255.

16 Cfr., a este respecto, y por todos, P. De VeGA, "Mussolini:...", cit., págs. 251-252. 
dicalistas del socialismo democrático, que muchas veces se limitaba al ejercicio de un "radicalismo estético" ${ }^{17}$ con el que, sin poner en realidad en discusión las bases legitimadoras del Estado Constitucional democrático y social, adoptaban una actitud de "un revolucionarismo aparente" (Jürgen Habermas) con el que pretendían evitar males mayores - supuesto, al decir de Nigel Townson ${ }^{18}$, de Araquistain y Largo Caballero desde 1933, cuando adoptan esta táctica por temor a la hipótesis, y como mecanismo (por cierto, frustrado en la práctica) para evitarla, de que Alcalá-Zamora y Lerroux pudieran entregar el poder efectivo de la República española a las derechas no republicanas o clara y abiertamente monárquicas, y que mantendrían hasta mayo de 1937, con el cese del líder sindical como Presidente del Gobierno-, y recelosos del carácter internacionalista del comunismo, creyó encontrar en el discurso irracionalista, pseudo-revolucionario, quiliástico y ultranacionalista del fascismo la solución a sus problemas y precaria situación.

Nadie ignora las consecuencias que esa vis atractiva de los totalitarismos de derechas tuvo para la articulación de la convivencia pacífica entre los hombres, que es, en rigor, el fin último del Derecho Constitucional, en la Europa del período entre guerras. El acceso al poder de las organizaciones fascistas, - ya fuera merced a su triunfo electoral, ya gracias a un golpe de Estado, ya como consecuencia de su victoria en una atroz, cruel, estúpida e injustificada guerra civil—, supuso la destrucción del proyecto democrático que, por fin, había comenzado a adquirir auténtica entidad y realidad en el Viejo Continente. Y, con ello, la, de una suerte u otra, destrucción del propio Estado, que, identificado, al menos desde las dispersas y asistemáticas especulaciones teóricas de Maquiavelo, con el ejercicio de la virtud política o, incluso, con esta misma ${ }^{19}$, había sido comprendido tanto por liberales, —como, por ejemplo, Montesquieu ${ }^{20}$ - , como por demócratas, —como, por ejemplo, Rous$\mathrm{seau}^{21}$ - , como el amor a la patria, la igualdad y las leyes que libremente se han dado los ciudadanos.

Ahora bien, el que la dinámica política, condicionada por una gran crisis económica y por la existencia de unos fuertes sentimientos nacionalistas que se sentían heridos, condujera a un patente e innegable fracaso, no autoriza, sin embargo, a negar o a ignorar la importancia que revistió el cambio político que se operó tras el fin de la Primera Guerra Mundial. Transcendencia que se concreta en una serie de transformaciones de orden jurídico, político, social

17 Sobre este concepto, cfr., por todos, P. De Vega, "Para una teoría política...", cit., pág. 44.

18 Cfr. N. Townson, La República que no pudo ser. La política de centro en España (19311936), Madrid, 2002.

19 Cfr., a este respecto, y por todos, P. De VeGa, "La Democracia como proceso...", cit., pág. 470 .

20 Cfr. Montesquieu, Del espiritu de las leyes, cit., "Advertencia del autor", pág. 5, y Libro III, cap. III, págs. 19-21.

21 Cfr. J.-J. Rousseau, Du Contrat Social..., cit., Libro II, cap. VI, págs. 75, en nota, Libro III, cap. IV, pág. 108; Discurso sobre la economía política (1755), Madrid, 1985, I, págs. 13 y ss.; II, págs. 22-25. 
y económico, con las que se lleva a cabo una ruptura radical y frontal con el modelo anterior. Tanto es así, que bien podemos afirmar que no resulta en modo alguno errónea la opinión de aquéllos que consideran que el nacimiento del moderno Estado Constitucional democrático y social, no puede explicarse como una mera evolución del viejo Estado Constitucional liberal. Antes al contrario, ocurre que la naturaleza y profundidad de estas transformaciones es tal, que, en realidad, habría que entender que el Estado Constitucional democrático y social se erige sobre las ruinas, o las cenizas, del viejo edificio liberal.

En haber tratado de articular en un sistema jurídico coherente todos esos cambios que la realidad social y política imponían como medio para superar la situación de crisis total a la que había llegado el Estado liberal, es donde, justamente, radica la grandeza del período entre guerras. Sin duda alguna, en ello se encuentra su decisiva contribución al proceso de consolidación del Derecho Constitucional europeo. Y es que, como nadie puede ignorar, los hombres que protagonizaron los diversos procesos constituyentes de aquellos años, trataron de consagrar en el más alto nivel normativo del Estado una serie de soluciones que, en último extremo, permitirían hacer reales y efectivos todos aquellos principios y valores que determinaron históricamente el nacimiento del propio Estado Constitucional, en un contexto político, social y económico que poco, o nada, tenía que ver con el existente a finales del siglo XVIII.

El Derecho Constitucional de la época weimariana se presenta, de cualquier modo, como el más serio e importante intento por configurar de manera definitiva al Estado como ese instrumento de liberación del hombre frente al dominio de otros hombres. Su importancia y transcendencia son difícilmente discutibles. Sobre todo, si se toma en consideración que las soluciones adoptadas en la época de la República de Weimar serían, prácticamente, las mismas que se aceptarían y generalizarían en el constitucionalismo surgido tras el fin de la Segunda Guerra Mundial, y que tan sólo comenzarían a ser cuestionadas en la última década del siglo xx cuando, como consecuencia del acceso al poder de las posturas ultraconservadoras y la caída del comunismo, el neoliberalismo tecnocrático procedió a discutir la propia legitimidad del Estado Constitucional y, en todo caso, a propugnar su substitución por una hipotética sociedad constitucional mundial.

Las Constituciones aprobadas entonces, operaron una ruptura radical y absoluta con el modelo jurídico y político anterior. Ruptura que se materializaría en todos los ámbitos.

En lo político, lo anterior se concretó en la creación de una situación jurídico-política para los ciudadanos que era, de modo indiscutible, total y absolutamente distinta a la que tenían en el Estado Constitucional liberal. En efecto, fue, justamente, con el constitucionalismo surgido después de la Primera Guerra Mundial cuando se pusieron definitivamente las bases para que la libertad civil dejase de ser un mero catálogo de derechos condenado, de manera inevitable y fatal, a disolverse en el ámbito de la retórica y de las bue- 
nas intenciones, para pasar a gozar de una auténtica entidad y realidad. Aceptar esto no ha de ser, en nuestra opinión, muy difícil, ni complicado.

Basta, en este sentido, con recordar que, como magistralmente ha indicado Pedro De Vega ${ }^{22}$, al menos desde las dispersas y asistemáticas reflexiones de Maquiavelo y Guiccardini se ha aceptado que el individuo sólo puede ser libre cuando todos los miembros de la Comunidad Política, gobernantes y gobernados, obedecen unas leyes tendentes a evitar el dominio de unos hombres sobre otros (vivere libero), las cuales, y esto es lo importante, y donde, por lo demás, reside la gran ruptura del pensamiento político moderno respecto del clásico y el medieval, son obra de los propios ciudadanos, - el Pueblo como entidad real, concreta e histórica-, en el ejercicio de la virtud política (vivere civile). Con esta ponderada combinación del vivere libero y del vivere civile, Maquiavelo, y quienes, con él, participaban en las reuniones que los Rucellai organizaban en sus Orti Oricellari, creaban las bases intelectuales para hacer real aquel quiasmo conforme al cual no hay Libertad sin Democracia, ni Democracia sin Libertad.

De todos debería ser conocido que esta idea del autor de "El Príncipe" tendría una más que sobresaliente presencia en el marco de todos aquellos principios y valores que históricamente determinaron el nacimiento del moderno Estado Constitucional. En efecto, los primeros revolucionarios liberalburgueses del Nuevo y del Viejo Continente, bajo la influencia de aquellos dos grandes maquiavelistas que, aunque sin poder declararlo abiertamente, fueron Montesquieu y Rousseau ${ }^{23}$, no trataron más que de proceder a la organización de la Comunidad Política desde la conciliación y combinación de las ideas de "Democracia" y "Libertad". Nacía, de esta suerte, el Estado Constitucional, y el constitucionalismo moderno, como un orden jurídico y político nuevo, cuya meta era, de manera concreta, poner en marcha un sistema de "libertad total" ${ }^{24}$.

Ahora bien, si esto es así, a nadie puede ocultársele que, pese a sus iniciales intenciones, los primeros revolucionarios liberal-burgueses acabaron configurando el Estado Constitucional liberal de un modo en que, de forma tan inevitable como fatal, aquél quedaba incapacitado para satisfacer su finalidad última. Lo que se explica por los esquemas conceptuales con los que liberales y conservadores, como fuerzas políticas mayoritarias, sino únicas, del proceso político, actuaban.

En este sentido, ha de tomarse en consideración que tanto conservadores como liberales partieron de aquel temor que Montesquieu ${ }^{25}$ había manifestado hacia el Pueblo y que, en última instancia, le condujo a configurar la Democracia, el ejercicio del vivere civile maquiavélico, como una democracia

22 Cfr. P. De Vega, "La Democracia como proceso...”, cit., págs. 468 y 473 y ss.

23 Cfr., en este sentido, y por todos, P. De VeGa, "La Democracia como proceso...", cit., pág. 492.

24 Cfr., al respecto P. De VEGA, "Constitución y Democracia”, cit., pág. 69.

25 Cfr. Montesquieu, Del espíritu de las leyes, cit., Primera Parte, Libro II, cap. II, págs. 12-13. 
representativa en la que, en todo caso, el ciudadano quedaba real y definitivamente apartado del proceso de toma de decisiones políticas fundamentales. Idea ésta que serviría a Sieyès para erigir a la Nación, concebida como un "cuerpo de asociados que viven bajo una ley común y están representados por la misma legislatura ${ }^{26}$, en el único sujeto capaz y legitimado para decidir la vida de la Comunidad Política. Con ello, y como certeramente ha hecho notar el Profesor De Vega ${ }^{27}$, liberales y conservadores procedían a la substitución de un Pueblo como entidad real, concreta e histórica, que es el elemento basilar y medular de la Democracia, por otro Pueblo, la Nación, que recupera esa naturaleza abstracta, metafísica e intemporal que, como, por ejemplo, nos enseña Felice Battaglia' ${ }^{28}$, tenía en el mundo clásico y medieval y de la que, como una de sus más grandes aportaciones a la Ciencia del Estado, la Política y el Derecho, le había despojado Maquiavelo. A ello debe añadirse que, partiendo de los temores expresados por Montesquieu, liberales y, sobre todo, conservadores - empeñados, como, p. ej., hacía Cánovas del Castillo, en convencer a todos de que el sufragio universal era «el triunfo del comunismo" ${ }^{29}$ - optaron por consagrar el sistema de sufragio restringido ${ }^{30}$, con el que el cuerpo político quedaba reducido a una única clase social: la burguesía.

El resultado de todo lo anterior, no podía ser, en verdad, más claro y, al mismo tiempo, dramático. Y éste no es más que el de la absoluta imposibilidad de hacer real y efectiva la libertad de los ciudadanos en el marco del Estado Constitucional liberal. Lo que, entendemos, se hace evidente desde los esquemas maquiavélicos. En efecto, lo que sucede es que, al haber erigido a la burguesía en la única titular del proceso político, la inmensa mayoría de los habitantes de los Estados europeos de finales del siglo XVIII, todo el XIX y primeros años del xx se veía obligada a observar y obedecer unas leyes que, por una parte, no eran obra suya, ni servían, por otra, y porque respondían a los intereses de una burguesía que, como había denunciado Lassalle ${ }^{31}$, difícilmente se mostraba interesada en favorecer al proletariado, para evitar el do-

26 E.-J. SIEYÈs, “¿Qué es el Estado llano? (1789), en el vol. ¿Qué es el Estado llano? Precedido del Ensayo sobre los privilegios, Madrid, 1988, cap. I, pág. 40.

27 Cfr. P. De Vega, "La Democracia como proceso...", cit., págs. 481-486, especialmente págs. 482-484.

28 Cfr. F. Battaglia, "El Estado y la moral", en el vol. Estudios de Teoría del Estado, Madrid, 1966, págs. 17-37.

29 Citado por C. Dardé, "El sistema político y las elecciones", en J. Tussell y F. Portero (eds.) y otros, Antonio Cánovas y el sistema político de la Restauración, Madrid, 1998, pág. 126.

30 Cfr. R. SMend, "Criterios del Derecho electoral en la Teoría alemana del Estado del siglo XIX" (1911), en el vol. Constitución y Derecho Constitucional, cit., pág. 6.

31 Cfr. F. Lassalle, vol. Manifiesto obrero y otros escritos, cit., págs. 109 y ss. ["Manifiesto obrero. Carta abierta al Comité general encargado de convocar un Congreso general obrero alemán" (1863)]; 183 y ss. ["Libro de lectura obrera. Discursos pronunciados por Lassalle en Frankfort am Main los días 17 y 19 de mayo de 1863"], y 285 y ss. ["Discurso renano. Las fiestas, la prensa y la reunión de diputados en Frankfort. Tres síntomas del espíritu público (20, 27 y 28 de septiembre de 1863)"]. 
minio de unos hombres sobre otros. No le faltará, de esta suerte, razón al Maestro De Vega cuando, refiriéndose al régimen de la libertad en el constitucionalismo liberal, escribe que "Peregrina la libertad en la Arcadia feliz de la sociedad, pronto se pudo constatar que, [...], el ejercicio del vivere libero se transformaba en el ejercicio del dominio de los intereses más poderosos sobre los más débiles. Lo que, [...], representaba, [...], la más abyecta forma de opresión y dominación, pues al convertirse unos hombres en meros instrumentos para que otros pudieran satisfacer sus ambiciones, no se hacía más que consagrar lo que Aristóteles consideraba la esencia misma de la esclavitud, ${ }^{32}$.

Sería con la substitución del Estado Constitucional liberal por el Estado Constitucional democrático y social cuando, como hemos dicho, la libertad de los ciudadanos, y no sólo la de los burgueses ${ }^{33}$, comenzase a ser real y efectiva. Y ello se produjo por una circunstancia que no era, o al menos no exclusivamente, de orden jurídico, sino político. En efecto, fue la definitiva conquista del sufragio universal, que, como contenido esencial del pensamiento democrático ya desde el mundo clásico — recuérdese, en este sentido, que fue ya Solón, el primer hombre de carne y hueso que merece ser calificado como político en Europa (Bengtson ${ }^{34}$ ), quien sostuvo la idea de que el gobierno democrático de la Comunidad Política requería la participación activa de todos los ciudadanos ${ }^{35}$ - , se había erigido en el principal problema de la vida política decimonónica ${ }^{36}$, lo que permitió aquella transformación. Y es que al estar ahora representadas en el Parlamento todas las clases sociales, y al ser la ley el resultado del proceso de discusión y confrontación de sus respectivos intereses, es cuando únicamente pudo hacerse real aquella idea que, adelantada por Maquiavelo, había defendido apasionadamente Rousseau $^{37}$, conforme a la cual en el Estado democrático el ciudadano no se obedece más que a sí mismo y, con ello, asegura su libertad al cumplir los mandatos de la ley que libremente se ha dado.

No fue ésta la única transformación que conoció la libertad civil en el tránsito del constitucionalismo liberal al constitucionalismo democrático y social. Junto a ella, se verificaría otra de carácter cualitativo, que se manifestaría, de modo fundamental, en el orden económico y social. Nos referimos, claro está, al hecho que con el nacimiento del Estado Constitucional democrático y social, se procedió a la substitución de la libertad liberal, que era, ante todo y sobre todo, una libertad económica, y cuyos titulares eran, básicamente, los miembros de la burguesía, por la libertad democrática que se configura como una Libertad en la Igualdad.

32 P. De Vega, "La Democracia como proceso...", cit., pág. 491.

33 Sobre estos conceptos, cfr., por todos, H. Heller, "Ciudadano y bugués" (1932), en el vol. Escritos políticos, cit., págs. 241-256.

34 Cfr. H. Bengtson, Historia de Grecia, Barcelona, 2005, pág. 81.

35 Cfr. J. Burckhardt, Historia ..., cit., vol. I, pág. 234-235.

36 Cfr. P. De VeGA, "La función legitimadora del Parlamento", en F. Pau Valls (ed.) y otros, Parlamento y opinión pública, Madrid, 1995, pág. 238.

37 Cfr. J.-J. Rousseau, Du Contrat Social..., cit., Libro I, cap. VI, pág. 51. 
Como no podría ser de otra forma, este substancial cambio sería recogido en el Derecho positivo de la época, y, naturalmente, por el Derecho Constitucional, teórico y práctico, nacido tras el fin de la Primera Guerra Mundial. Ahora bien, si esto es así, es, sin embargo, en el ámbito de lo político y de lo ideológico donde se encuentra el origen y el fundamento último de esta tan esencial transformación. Si se me permite utilizar el estilo empleado por Smend en su "Constitución y Derecho Constitucional", diría que lo anterior ha de ser para todos evidente y que nadie podría ponerlo en duda, salvo que se sea como aquel ultra-positivista jurista persa, al que, en 1981, se refirió el Profesor Cruz Villalón, empeñado en conocer la realidad constitucional ${ }^{38}$ española con la mera lectura de la Constitución de 27 de diciembre de 1978.

Fue, en efecto, el acceso de demócratas, demócratas radicales y socialistas democráticos (marxistas o no), al Parlamento, e, incluso, su elevación a la posición de fuerzas políticas mayoritarias, lo que permitió positivizar en el ámbito del Derecho, fundamental y ordinario, la comprensión de la Libertad como Democracia e Igualdad. Lo que se llevó a cabo con la adopción de medidas tales como, por ejemplo, $1 .^{\circ}$ ) la puesta en marcha de una política fiscal que, primando la imposición directa sobre la, sin duda alguna mucho más injusta, imposición indirecta, y dotándola de un carácter progresivo, haría que fuesen los individuos económicamente más poderosos quienes realizasen una mayor contribución a la hora de sufragar la acción del Estado, de la que se beneficiarían todos los ciudadanos y, de manera especial, los social y económicamente más

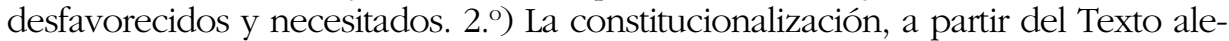
mán de 1919, y siguiendo, de un modo u otro, el ejemplo de lo hecho, en 1917, por los mexicanos en Querétaro, de los derechos sociales ${ }^{39}$, en cuya virtud el Estado comienza a asumir la tarea de proteger a sus ciudadanos, singularmente a los más necesitados, con la prestación de una serie de servicios (educación, sanidad, etc.) que en el marco del Estado Constitucional liberal quedaban confiados a la iniciativa privada, cuando no a la beneficiencia. $\left.3 .^{\circ}\right)$ El establecimiento de límites a la propiedad privada, que, sin embargo, estaría constitucionalmente garantizada (cfr., a este respecto, art. 27 Const. mexicana 1917; art.153 Const. alemana 1919; art. 44 Const. de la República española de 1931), cuya finalidad era la de limitar las desigualdades entre sus ciudadanos

38 Importa advertir que, como en otras ocasiones, el término "realidad constitucional" no es utilizado aquí en el sentido que a esta expresión le da, p. ej., K. Loewenstein [cfr. Teoría de la Constitución, Barcelona, 1979, 2. ${ }^{\text {a }}$ ed., págs. 216 y ss.; "Verfassung und Verfassungsrealität (Beiträge zur Ontologie des Verfassung)", Archiv des öffentlichen Rechts, Bd. 77, 4 (1951-1952), págs. 387 y ss.], esto es, como "realidad jurídico-normativa" que puede, o no, estar en consonancia con la "realidad político-social" subyacente, lo que, como observa K. STERN, "más bien obscurece que clarifica el problema" (Derecho del Estado de la República Federal Alemana, Madrid, 1987, págs. 244). Por el contrario, lo hacemos con el sentido que, partiendo de la concepción smendiana de la Constitución como norma y como realidad, le otorga un Konrad Hesse (cfr. "Concepto...", cit., pág. 30). Lo que, traducido en otros términos, significa que únicamente cabe hablar de realidad constitucional cuando se verifique la adecuación entre realidad jurídico-normativa y realidad político-social.

39 Sobre este particular, cfr., por todos, P. DE VEGA, "La crisis...", cit., pág. 124. 
derivadas de la condición de ser, o no, propietarios. $4^{\circ} .^{\circ}$ El reconocimiento constitucional de la posible intervención del Estado en la vida económica - anatematizada por liberales y conservadores desde la aceptación incondicionada y total de la idea de Constant ${ }^{40}$ de que aquélla constituía el mayor de los atentados posibles a la libertad de los hombres-, ya fuera en su condición de propietario, ya mediante la planificación del proceso productivo, ya fuese, por último, a través de la regulación del mercado con una política de control del precio de los productos, de manera especial los de primera necesidad.

Medidas todas éstas que, innecesario debiera ser advertirlo, no son más que la positivización en el ámbito jurídico de lo que las fuerzas progresistas, de modo fundamental el democratismo radical y el socialismo democrático, defendían y propugnaban en el ámbito de la confrontación política partidista. De ello no puede haber duda alguna si se toma en consideración lo que en los distintos procesos revolucionarios constituyentes de la época, defendieron las organizaciones de la izquierda burguesa y obrera. Baste aquí con recordar lo que, con oratoria siempre limpia, contundente y brillante, Manuel Azaña había determinado como el fin primario y prioritario de la revolución española: "Pero hay una regla general que yo proclamo aquí, no como aliciente para atraer a los dudosos, ni menos aún como recompensa de posibles colaboraciones, sino como un principio que se nos impone en conciencia y que habremos de aplicar [...]; es este: la República española tendrá que ser no sólo respetuosa con los derechos del trabajo, y garantía de sus reivindicaciones, sino propulsor y estímulo en la obra de despertar las conciencias más atrasadas y de levantarlas a un rango superior de humanidad y de ciudadanía " ${ }^{41}$.

La izquierda iniciaba, de este modo, una práctica política que se encuentra en una absoluta, inequívoca e innegable, consonancia con el que, desde siempre, ha sido el núcleo central de las ideas democráticas. Recuerdese, a este respecto, que fueron las contundentes afirmaciones realizada, en su "Eunomia", por Solón sobre el que la legislación ha de tener como fin primario el establecimiento de la igualdad y la justicia entre ricos y pobres y de la concordia entre ellos ${ }^{42}$, que, como, de la mano de Pedro de Vega, hemos visto ya, serían recuperadas en el mundo moderno por Maquiavelo y Guiccardini, las que, en esencia y en último extremo, condujeron al utópico Harrington $^{43}$ a propugnar la organización del Estado como República equitativa, cuya vida ha de regirse por unas leyes aprobadas, o al menos consentidas, por el pueblo. Más explícito, y mucho más radical, se mostraría aún Rousseau.

A lo largo de toda su obra, el "Ciudadano de Ginebra" concebiría la República, la Comunidad Política democrática, como aquel Estado fuerte, que

40 Cfr. B. Constant, "Principios de política" (1815), en el vol. Escritos políticos, Madrid, 1989, pág. 8; "De la libertad...”, cit., págs. 75, 76 y 82, por ejemplo.

41 M. AZAÑa, "La revolución en marcha. Alocución en el mitin republicano de la plaza de toros de Madrid, 29 de septiembre de 1930", en M. Azaña, Discursos polítios, cit., pág. 82.

42 Cfr., en este sentido, y por todos, H. Bengston, Historia ..., cit., pp 81 y ss.

43 Cfr. J. Harrington, La república de Océana (1656), México, 1987, passim, y en particular, págs. 75-78. 
protege a sus ciudadanos, les presta todos los servicios básicos que les permita gozar de una vida digna, y que, haciendo de la Igualdad el primer mandato de su Constitución, se encuentra obligado a adoptar cuantas medidas fuesen necesarias para eliminar, en la medida de lo posible, la desigualdad moral o política. Propuestas éstas sobre las que se profundizaría en el ámbito de las ideas socialistas. Así nos encontramos con que, partiendo de las formulaciones democráticas, Fitche ${ }^{44}$, el primer socialista moderno y científico (Heller) que, por lo demás era un gran admirador de Rousseau y, sobre todo, de Kant, no dudaría en afirmar que el deber fundamental de la Comunidad Política es la de lograr la igualación de los ciudadanos al poner a cada uno en posesión de lo que le corresponde y protegerlo, lo que únicamente podría cumplir si se configura como un Estado que interviene en la economía sometiendo el mercado a la legislación y jurisdicción estatal, que planifica la vida económica y, finalmente, controla el comercio nacional e internacional.

De cualquier modo, lo que realmente nos interesa destacar es que todas aquellas medidas jurídicas, reflejo inmediato y directo de las propuestas político-ideológicas de los progresistas y que, con mayor o menor entusiasmo, se vieron obligados a aceptar liberales y conservadores, no hacían más que poner, en el solar devastado del viejo Estado Constitucional liberal, las primeras piedras de los cimientos de una nueva forma política. Nueva forma política que, a la poste, consagraba al Estado como el mejor, y más importante, instrumento de liberación de los hombres. Nos referimos, claro está, al Estado social que, habiendo conocido una primera, y tímida, manifestación en nuestra Segunda República —en cuya Constituyente participó el republicano Manuel Pedroso, Catedrático de Derecho Político de la Universidad de Sevilla, y discípulo directo de Heller-, se consolidaría y generalizaría en el constitucionalismo europeo surgido después de la Segunda Guerra Mundial. Su primer y más lúcido teórico, Herman Heller ${ }^{45}$, definió esta nueva forma política como aquella Comunidad que, recuperando el contenido material del Estado de Derecho e impregnándolo de democracia social, persigue alcanzar el mayor grado posible de homogeneidad social y, para ello, se configura como un Estado fuerte, interventor, prestacional y redistribuidor de la riqueza.

B) WeIMAR COMO INICIO DE LA COMPRENSIÓN DE LOS TeXTOS CONSTITUCiOnAlES COMO VERDADERAS CONSTITUCIONES EN EUROPA, Y ALGUNOS PROBLEMAS PARA SU FORMULACIÓN DOGMÁTICA

Fue, sin duda, en el orden jurídico donde se verificaron las más espectaculares y radicales transformaciones en el constitucionalismo europeo. En

44 Cfr. J. G. Fichte, El Estado commercial..., cit., Libro Primero, capítulo primero, págs. 16, 20 y 41 y ss; Libro Segundo, pág. 86.

45 Cf. H. Heller, "Democracia política...", cit., pp257-258; "¿Estado de Derecho o dictadura?", cit., passim; "Metas y límites...", cit., págs. 79 y ss. 
efecto, ocurre, como nadie ignora ni, por lo demás, podría hacerlo, que la aprobación del Texto alemán de 1919 supuso la apertura en Europa de un proceso, que culminaría tras el fin de la Segunda Guerra Mundial, en virtud de cual los Códigos Fundamentales pasaron, por fin, a ser comprendidos como auténticas Constituciones. Lo que, naturalmente, se traducía en un cambio substancial y radical respecto de la situación existente en el marco del Estado Constitucional liberal. Cambio éste que, a la postre, se concretaba en que, al equiparar de una manera plena y total la tradición jurídico-política europea con la tradición jurídico-constitucional estadounidense, la forma política "Estado Constitucional" se hacía definitivamente real, y adquiría auténtica entidad y existencia histórica, en el Viejo Continente ${ }^{46}$.

Ahora bien, si esto es así, es menester advertir, de manera inmediata, que lo anterior no es, ni mucho menos, el resultado de la especulación teórica de los juristas en sus despachos académicos alejados, según los mandatos del primer positivismo jurídico formalista, de la realidad político-ideológica, social y económica. Por el contrario, nos encontramos con que esta nueva comprensión de los Textos Constitucionales no son sino la lógica consecuencia de los cambios que, con el fin de la Primera Guerra Mundial, se habían producido en aquello que Ferdinand Lassalle denominó los "factores reales del poder" ${ }^{47}$, y que a partir de Mortati identificamos con el término "Costituzione in senso materiale " 48 .

En este sentido, importa recordar que, como, de una suerte u otra, ha quedado ya dicho, la entrada de los partidos demócratas, demócratas radicales y socialistas en los distintos Parlamentos nacionales, y, sobre todo, su ascenso a la condición de fuerzas políticas mayoritarias en el Estado, determinaron que la confrontación entre el principio monárquico y el principio democrático, que había presidido la vida política y jurídica europea desde la Revolución francesa hasta 1919, conociese una solución bien diversa a la que se le había dado en el constitucionalismo liberal, y, de modo fundamental, a lo largo del siglo XIx. En efecto, el triunfo de las fuerzas políticas progresistas supuso la definitiva expulsión de las ideas y del principio monárquico del panorama político europeo. Las ideas y el principio democrático, propugnados por los progresistas y, con mayor o, más bien, menor entusiasmo, aceptadas por liberales y conservadores, se erigían, de esta suerte, en el único criterio inspirador, legitimador, fundamentador y ordenador del sistema jurídico-político.

$\mathrm{Ni}$ que decir tiene que esta substancial transformación en la vertebración del Estado, habría de generar unas más que sobresalientes consecuencias en el orden jurídico. De una manera muy particular, y por lo que a nosotros in-

46 Sobre este particular, y por comodidad, cfr. J. RuIPÉREZ, El constitucionalismo democrático..., cit., págs. 128-134, y bibliografía allí citada.

47 Cfr. F. Lassalle, "¿Qué es una Constitución?" (1862), en el vol. ¿Qué es una Constitución? ¿Y ahora? Apéndice polémico, Barcelona, 1984, págs. 84 y ss.

48 C. Mortati, La Constitución en sentido material (1940), Madrid, 2000. 
teresa, éstas se manifestarían en cuanto al valor que, ahora, y a diferencia de lo que había sucedido en la Europa de finales del siglo XVIII, todo el XIX y primeros años del xx, se otorgaba a la Ley Constitucional . Lo que, a nuestro juicio, no ha de resultar muy complicado de comprender.

Fue, en efecto, la aceptación total, y sin ambages de ningún tipo, de la idea democrática de que, por decirlo con Heller ${ }^{49}$, el "Pueblo como unidad", y en el ejercicio del Poder Constituyente, puede, en la medida en que es el soberano, imponer su voluntad al "Pueblo como diversidad", incluso a aquéllos que no están conformes con la decisión mayoritaria, que se había realizado en el plano de la confrontación política e ideológica, la que únicamente permitió, en el plano, jurídico, el que los Códigos Jurídico-Políticos Fundamentales, comprendidos ahora como verdaderas y auténticas Constituciones, pudieran comenzar a desplegar todos sus efectos. Entre ellos, y como no podría ser de otra forma, el de esa singular fuerza normativa que se esconde bajo la expresión la "Constitución como norma jurídica". Nos sumamos, una vez más, y como a nadie puede sorprenderle, a la opinión de Pedro De Vega. Ofrece el Maestro la explicación de este fenómeno en los siguientes términos: "La indiscutibilidad ideológica de los principios y el acuerdo en los presupuestos en los que descansa la idea de Constitución, es lo que ha permitido al constitucionalismo surgido [con la aprobación del Texto de Weimar, y consolidado] a partir de la Segunda Guerra Mundial, ponderar debidamente su dimensión jurídica y su proyección normativa " ${ }^{50}$.

Es necesario advertir, sin embargo, que esta espectacular y substancial variación en la concepción de las Constituciones, no se debió tan sólo a la mera aceptación de las ideas y del principio democrático por parte de los operadores políticos de los distintos Estados. No puede olvidarse, a este respecto, que ya en el momento de la Revolución francesa, los primeros revolucionarios liberal-burgueses habían proclamado, de manera enfática y solemne, que la nueva forma de organización estatal, y en aras a convertirla en el escenario donde se desarrollaría un sistema de libertad total, se articularía en torno a los principios democrático, liberal y de supremacía constitucional. Declaración ésta que, como nadie ignora, no generó las consecuencias, ni los efectos, que a partir del período entre guerras van a producirse en el Derecho Constitucional europeo. Y es que, en verdad, los distintos Constituyentes de la época weimariana no se limitaron a realizar una aceptación formal del principio democrático, sino que, por el contrario, procedieron a la adopción de una serie de medidas jurídicas que tendían a hacer realmente eficaz a aquél, y con las que, en definitiva, el constitucionalismo democrático y social venía a corregir y a superar todas aquellas grandes fallas que presentaba en Estado Constitucional liberal.

49 Cfr., en este sentido, y para el principio general expuesto, H. Heller, La soberanía..., cit., págs. 166-168. Para los conceptos "Pueblo como unidad" y "Pueblo como diversidad", así como para su operatividad en el marco del principio anterior, cfr. H. Heller, "Democracia política...", cit., pág. 262, en relación con lo dicho en págs. 260-261.

50 P. De Vega, "Prólogo" a A. DE CABo (ed.). La Constitución española de 27 de diciembre de 1978, cit., págs. XX-XXI. 
Tales medidas, que, lógicamente, se presentaban como soluciones jurídicas a los problemas reales del sistema jurídico-constitucional, tenían, no obstante, un claro origen y fundamento político e ideológico. Veámoslo, aunque sea de modo sintético.

En este sentido, nos encontramos, en primer lugar, con que la, más o menos entusiasta, aceptación incondicionada por parte de progresistas, liberales y conservadores de aquella idea democrática que, en el momento justamente anterior al proceso revolucionario liberal-burgués americano, el reverendo John Wise había sintetizado en que, como consecuencia de la celebración del pacto social, "Un Voto o un decreto [la Constitución] debe inmediatamente establecer una particular forma de Gobierno sobre ellos, Y si han convenido en el primer Compact una cláusula expresa de que se estará en todo lo concerniente a la forma de Gobierno a la decisión resultante del primer Voto: Todos ellos estarán obligados por la mayoría a aceptar la forma particular así establecida, aun cuando su propia Opinión privada, les incline hacia algún otro modelo" ${ }^{51}$, obligó a los Constituyentes europeos desde 1919 a la necesaria aceptación de otra idea central y medular del pensamiento político democrático. Nos referimos, ocioso debiera ser el advertirlo, al principio conforme al cual la obediencia y respeto a la ley democrática ha de ser obligatoria, naturalmente, para los gobernados, pero también, y esto es lo importante y lo que en realidad resulta relevante y transcendente, para los gobernantes. Ocurre, además, que estos últimos, que, a diferencia de los gobernados, tan sólo pueden hacer aquello que la ley expresamente les permite, se encuentran especial y singularmente vinculados por el Derecho, en el sentido de que, como, de modo harto contundente, indicó Rousseau, «el interés más urgente del jefe y su deber más indispensable es velar por la observancia de las leyes de las que es ministro y sobre las cuales se funda toda su autoridad. Si debe procurar que los otros las observen, con más razón deberá observarlas él mismo pues goza de todos sus favores, ya que su ejemplo tiene tal fuerza que, aun cuando el pueblo quisiese soportar que el jefe le libere del yugo de la ley, éste deberá guardarse de aprovechar tan peligrosa prerrogativa [...]. En el fondo, como todos los compromisos de la sociedad son recíprocos por su naturaleza, no es posible ponerse por encima de la ley sin renunciar a sus ventajas, [...]. Por la misma razón, ninguna exención de la ley será jamás aplicada por título alguno en un gobierno bien administrado. [...]. Y así, en efecto, la primera de las leyes es la de respetarlas" ${ }^{52}$.

La preocupación por dotar a este principio de un contenido real y efectivo, ha sido una auténtica constante en la Teoría Politica. El Profesor De Vega, en su mencionada conferencia "Republicanismo y Democracia", nos ha enseñado que ya en la Grecia clásica se ocuparon de tratar de asegurar la obediencia a la ley por parte de los gobernantes con el establecimiento de

51 J. Wise, A Vindication..., cit., pág. 33.

52 J.-J. Rousseau, Discurso sobre la economía política, cit., I, págs. 15-16. 
ciertos límites a la facultad legislativa de éstos. De una manera más concreta, advierte mi muy querido y admirado Maestro que fue Solón —a quien, con toda justicia, puede considerarse el iniciador de aquella corriente teórica y práctica que, pasando por los gobiernos de Pisístrato, Clístenes y Temístocles, dio origen a la democracia ática con Pericles (Bengtson, Guthrie ${ }^{53}$ ) - el primero de los pensadores demócratas que ofreció una solución al respecto. En efecto, enfrentado Solón a la antinomía que se derivaba de la doble idea de que, por un lado, la Libertad depende de que todos los miembros de la Comunidad Política obedezcan escrupulosamente la ley, y, por otro, la de que, en nombre de la Democracia, el Pueblo puede, en todo momento y en cuanto señor de la Comunidad, modificar, substituir o derogar las leyes, no encontró el gran Legislador otra salida que la del establecimiento en la polis de una norma suprema a la que todos los ciudadanos, gobernantes y gobernados, debían obediencia y, así mismo, la del establecimiento de límites a las posibilidades de las asambleas para cambiar las leyes. Nacía, de esta suerte, la distinción entre nomoi, que, en tanto en cuanto eran las normas jurídicas en las que se contenían los elementos implícitos de la polis, han de ser inalterables, y psefismata, que, como leyes o decretos aprobados por la asamblea, serían siempre modificables, respetando, eso sí, los nomoi.

Ahora bien, si esto es así en el mundo clásico, y si bien es verdad que, recogiendo el anterior pensamiento, no faltaron en la Edad Media construcciones que pretendían hacer real el principio de que también el gobernante estaba sujeto al Derecho, - entre las que, sin que quepa ningún género de duda, destacan las de Juan de Salysbury y Marsilio de Padua-, es lo cierto, empero, que todas estas tesis no pasaron de ser unas meras teorías elaboradas por los que Fichte ${ }^{54}$ denomina "filósofos", es decir, estudiosos de la Política y el Derecho, que, aunque con un valor innegable e indiscutible como precedentes remotos del actual principio de supremacía constitucional, no gozaron en la práctica de efectividad alguna. El propio Pedro De Vega, con la brillantez, rigor y precisión que le son característicos, se ha encargado de poner de manifiesto esta circunstancia. Así, escribe que "constituiría una falsificación de la realidad y de la historia, el pensar en la existencia de leyes superiores en el mundo clásico y medieval. Todavía en los siglos XVI y XVII, en los que se acuña en término Lex Fondamentalis, y se mantiene la doctrina de la bereuse impuissance del rey de violar esas leyes, el escepticismo ante las mismas era evidente. [...] A la negación en el orden práctico de una ley superior, correspondió también un más que notable enmarañamiento teórico en el orden conceptual. Por doquier se hablaba de leyes fundamentales, pero no se sabía ni lo que eran, ni en qué consistían. A veces la ley fundamental se hacía

53 Cfr. H. Bengtson, Historia..., cit., pág. 84; W. K. C. Guthrie, Historia de la filosofía griega, Barcelona, 2005, t. III, págs. 30-31.

54 Cfr. J. G. Fichte, El Estado comercial..., cit., "[Dedicatoria] A su Excelencia: Señor de Struesse, Ministro privado del Estado Real de Prusia y Caballero de la Orden del Águila Roja", pág. 6. 
coincidir con la ley divina. En otras ocasiones se vinculaba a la tradición medieval de la "lex terraem, 55 .

Hubo de esperarse a finales del siglo xviII para que, por vez primera en la Historia, la idea de una Ley Superior, a la que, por ser tal, gobernantes y gobernados se encuentran sujetos por igual, dejase de ser una mera aspiración teórica de los pensadores demócratas, para convertirse en una entidad real y efectiva ${ }^{56}$. Lo que se logró por cuanto que fue en los grandes procesos revolucionarios liberal-burgueses de América y Francia cuando, por fin, se consiguió articular un mecanismo jurídico en virtud de cual el principio de supremacía constitucional, y, con él, el principio democrático que le sirve de base y fundamento, encontró su plena y total eficacia. Y ese mecanismo jurídico no es otro que aquel principio de rigidez que, si en el plano teórico había tenido en la obra de Lord Bryce ${ }^{57}$ su primera y definitiva formulación, en el plano normativo recibiría una primera, no totalmente adecuada y, desde luego, incompleta, positivización en la Constitución de Massachussets de $1980^{58}$, para hacer, finalmente, su definitiva entrada en la Historia cuando los Founding Fathers en Filadelfia procedieron a aprobar el artículo V de la Constitución estadounidense ${ }^{59}$, en el que, —como señalan La Pergola y De Vega ${ }^{60}$ - , rompiendo los esquemas pactistas propios de la Confederación de Estados, dieron cabida al principio de la mayoría cualificada para la válida aprobación de la reforma constitucional.

En definitiva, la supremacía constitucional, en virtud de la cual el Código Fundamental puede desplegar toda su potencialidad jurídica y política, apa-

55 P. De Vega, "Supuestos políticos...”, cit., págs. 403-404.

56 Cfr., en este sentido y por todos, J. BARTHÉLEMY y P. Duez, Traité de Droit Constitutionnel, París, 1933, nueva edición, pág. 188; H. Finer, Teoría y práctica del Gobierno moderno, Madrid, 1964, pág. 199; P. Bastid, L’idée..., cit., pág. 19.

57 Cfr. J. BRYce, Constituciones flexibles y Constituciones rígidas, Madrid, 1988, passim.

58 En relación con esto, debemos a Charles Borgeaud (Établissement..., cit., págs. 171-173 y 176 y ss.) la observación de que las Constituciones que los nacientes Estados americanos fueron aprobando con anterioridad a la Convención de Filadelfia, pese a responder, clara e inequívocamente, a la teoría democrática del Poder Constituyente del Pueblo, no contenían, como regla general, ninguna previsión sobre el modo en que podría llevarse a cabo su modificación formal. Con lo que, a nuestro juicio, no resultaría exagerado vincular todos estos Textos a los viejos documentos de gobierno ideados por el pensamiento político democrático que, a la postre, quedaban condenados en la práctica a carecer de una auténtica eficacia. La excepción a esta regla la representa la Constitución de Massachussets de 1780, la cual preveía un procedimiento especial, distinto del legislativo ordinario, para, en todo caso después de transcurridos 15 años desde su aprobación, llevar a cabo su revisión. Ahora bien, se trataba de un procedimiento que, como advierte el propio Borgeaud (op. cit., págs. 176-177), resultaba plenamente correcto para realizar reformas totales del Texto Constitucional, pero que, por el contrario, resultaba ciertamente inadecuado para atender a la hipótesis, mucho más frecuente, de la reforma parcial. No resulta, en tales circunstancias, exagerado afirmar que no fue, entonces, con el Texto de Massachussets, sino con la Constitución federal de 1787 cuando realmente hizo su entrada en la Historia el principio de rigidez, y que fue por emulación de esta última por lo que dicho principio se introdujo en las Constituciones estatales ya en el s. XIX, 187-189.

59 Cfr., a este respecto, A. Hamilton, J. Madison; J. Jay, El Federalista, cit., n. ${ }^{\circ}$ XLIII, págs.

60 Cfr. A. LA Pergola, Residui "contrattualistici" e struttura federale nell'ordinamento degli Stati Uniti, Milán, 1969, págs. 192-103; P. DE VEGA, "Supuestos políticos...”, cit., pág. 406. 
rece irremediablemente vinculado al establecimiento legal-constitucional de un procedimiento específico, distinto y, de manera usual, pero no necesariamente ${ }^{61}$, más agravado que el previsto para actuar sobre la legislación ordinaria, para llevar a cabo la modificación formal de la Constitución. Lo que, como es obvio, nos remite a la figura de la reforma constitucional, entendida, con Mortati ${ }^{62}$ y De Vega ${ }^{63}$, como aquella institución garantista cuya finalidad y función no son tanto la de permitir el cambio del Texto Constitucional, que, en todo caso, ha de ser siempre controlado y limitado, sino la de actuar como mecanismo de defensa de la Constitución. Y ello, por cuanto que, gracias a ella, se logra salvaguardar la voluntad soberana del Pouvoir Constituant frente a la caprichosa, cambiante y coyuntural actuación de los poderes constituidos.

A la vista de lo expuesto, a nadie podría, ni debería, extrañar que cuando, con el fin de la Primera Guerra Mundial, en Europa se verificó la aceptación plena, total y sin reserva de ningún tipo, del principio democrático, los diversos Constituyentes, haciendo buenas las consideraciones que, en su día, James Bryce ${ }^{64}$ había hecho al respecto, optasen por recuperar para las nuevas Constituciones el carácter rígido con el que habían nacido también en los procesos revolucionarios liberal-burgueses europeos de finales del siglo xviII, y del que, de manera que en modo alguno puede entenderse casual, fueron despojados por el constitucionalismo del liberalismo doctrinario. Pero, es menester advertirlo de forma inmediata, esta atribución del carácter rígido a los Textos Constitucionales se haría de un modo, y con un contenido y significado, bien distinto al que se le había otorgado en los albores del Estado Constitucional europeo.

En efecto, los Constituyentes de la etapa weimariana trataron de dotar al principio de rigidez de una auténtica y real eficacia. Eficacia de la que, de manera más que lamentable, se habían visto privados los Códigos Jurídico-Políticos Fundamentales de la Revolución como consecuencia de la sorprendente, y no menos absurda y, en todo caso, contradictoria con la propia lógica interna del Estado Constitucional ${ }^{65}$, concepción de Sieyès, conforme a la cual el Parlamento, como representante de la Nación soberana, se convierte, él mismo, en el auténtico soberano en el Estado y, además, actúa como tal en todo

61 Para la comprensión de la rigidez constitucional no como el mayor agravamiento y complejidad procedimental para llevar a cabo las reformas, sino como la existencia de ese procedimiento específico, y distinto del legislativo ordinario, para realizarlas válidamente, cfr., por todos, J. RuipéRez, "Estática y dinámica...", cit., págs. 56-64, donde se critica la confusión creada por el Tribunal Constitucional en la Declaración 1/1992, de 1 de julio, al mezclar los conceptos de rigidez y reforma expresa.

62 Cfr. C. Mortati, Istituzioni di Diritto Pubblico, Padua, 1985, 9. ${ }^{a}$ ed. reel. y puesta al día, t. II, pág. 1.225.

63 Cfr. P. DE VEGA, "La reforma constitucional", en la obra colectiva Estudios sobre el Proyecto de Constitución, Madrid, 1978, pág.220.

64 Cfr. J. Bryce, Constituciones flexibles..., cit., págs. 42, 50 y 112.

65 Cfr., a este respecto, y por todos, C. SснмітT, Teoria ..., cit., págs. 108-109; P. De Vega, La reforma constitucional..., cit., págs. 34-37 y 74-76. 
momento $^{66}$. Para superar y solventar la contradicción de la existencia de un Parlamento que, como poder creado por la Constitución, había de actuar sometido y dentro de la propia Constitución, pero que, en cuanto que poder soberano, absoluto e ilimitado, podría perfectamente imponer su nueva voluntad al Texto Constitucional, los Constituyentes del período entre guerras no encontraron mejor solución que la de aceptar y poner efectivamente en marcha aquél esquema normativo en el que aparecía la distinción entre Constitución, Ley de reforma constitucional y ley ordinaria, que a nivel orgánico se traducía en la distinción Poder Constituyente, Poder de Reforma y Legislador ordinario, cada uno de los cuales actuaría en su esfera propia, que, desde el primer momento, había sido creado por los hombres de la Convención de Filadelfia $^{67}$.

Ahora bien, no fue ésta la única transformación jurídica que el cambio político en cuanto al principio que actuaría como criterio legitimador y vertebrador del Estado, depararía en el constitucionalismo europeo. Y es que, en efecto, la aceptación incondicionada del dogma político de la soberanía popular, conforme al cual, como sabemos, el Pueblo soberano impone su voluntad a todos, condujo a los hombres del período weimariano a la convicción de que era menester articular algún mecanismo jurídico con el que, al hacer eficaz el principio de rigidez constitucional, se consiguiese poner definitivamente a salvo la voluntad del Constituyente frente a los eventuales ataques que, derivados de sus puntuales, coyunturales y cambiantes intereses, pudieran dirigirle las fuerzas políticas que, en cada momento, ocupasen los poderes constituidos. Se introducía, de esta suerte, en el Derecho Constitucional europeo el instituto del control de constitucionalidad de las leyes.

Cierto es, no obstante, que esta necesidad fue ya comprendida en el constitucionalismo pre-weimariano. Así, nos encontramos con que Georg Jellinek $^{68}$, —el autor, no nos cansaremos nunca de repetirlo, más lúcido, válido, útil y capaz del primer positivismo jurídico formalista-, hizo ya la acertada y oportuna observación de que de nada sirve prever un mecanismo específico, y especial, para modificar los Textos Constitucionales, si no se establece, junto a él, un órgano, el juez constitucional, competente para fiscalizar la actuación de los poderes constituidos para, de este modo, garantizar que todas las revisiones del Código Fundamental se verifiquen de acuerdo con el procedimiento legal-constitucionalmente establecido para tal fin, anulando, en su caso, todas aquellas normas ordinarias que contradigan la Constitución.

Ocurre, sin embargo, que la genial intuición de Jellinek se vería condenada a quedar como una brillante formulación teórica, cuyo valor como antecedente doctrinal en la forja del Derecho Constitucional europeo resulta in-

66 Sobre esta problemática, y por comodidad, cfr., por todos, J. RuIPÉREz, El constitucionalismo democrático..., cit., págs. 112-119.

67 Sobre el mismo, y también por comodidad, cfr. J. RuIPÉREZ, "Estática y dinámica...", cit., págs. 225-229, y bibliografía allí citada.

68 Cfr. G. Jellinek, Teoría General..., cit., pág. 406; Reforma..., cit., págs. 15 y ss., especialmente págs. 22 y ss. 


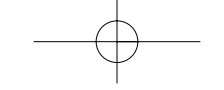

discutible, pero que en el terreno de la práctica jurídica y política se mostraba incapaz de ponerse en marcha. Y ello, como consecuencia directa de las limitaciones que la realidad política existente cuando él escribía, imponía. Dos son, de manera fundamental y básica, las causas que determinaban la anterior circunstancia. En primer lugar, no puede olvidarse que se trataba de un constitucionalismo que, elaborado y construido desde el principio monárquico, permitía la existencia de un poder: el monarca, que, por ser el depositario de la soberanía estatal, se situaba por encima de la propia Constitución, y al que se le permitía actuar al margen e, incluso, en contra de sus mandatos. En segundo término, ha de tomarse en consideración que la regla general del siglo XIX y primeros años del xx, fue la de que los instrumentos de gobierno se materializaban como Constituciones flexibles, en cuyo seno, y como muy bien han visto, por ejemplo, un Hans Kelsen o un Pedro De Vega ${ }^{69}$, no cabe plantear la problemática de la inconstitucionalidad de la ley, por cuanto que, al no prever un mecanismo específico para la Verfassungsänderung, la hipótesis de una ley posterior y contraria a la Constitución no podría entenderse como una transgresión de la misma, sino, por el contrario, como un supuesto válido de reforma constitucional.

Sería tan sólo con el triunfo de las ideas y del principio democráticos, operado gracias al substancial cambio de las fuerzas políticas mayoritarias, como el control de constitucionalidad pudo abrirse paso en el Viejo Continente. En efecto, fue la substitución del principio monárquico por el principio democrático como criterio legitimador y vertebrador de la Comunidad Política, lo que, en realidad, permitió la puesta en marcha del "Staatsgerichtsbarkeit" o "Verfassungsgerichtsbarkeit", y de los Tribunales de Estado (Staatsgerichtshoff des deutschen Reiches y Staatsgerichtshöfe des deutschen Ländern) en la República alemana de 1919, así como la de la justicia constitucional y los Tribunales Constitucionales en las Constituciones checoeslovaca de 29 de febrero de 1920, austriaca de 1 de octubre de 1920, y española de 9 de diciembre de 1931.

Lo de menos es detenerse aquí a indicar que la evolución que han tenido este instituto de la justicia constitucional y el órgano encargado de aplicarla se ha ido progresivamente separando del sentido y significado con el que fueron creados, de suerte tal que a finales de la pasada centuria los Tribunales Constitucionales, haciendo ciertas las apocalípticas previsiones de Carl Schmitt sobre el custodio constitucional, se han convertido, como señala el Maestro De $\mathrm{Vega}^{70}$, en uno de los factores que más, y con mayor transcendencia, han contribuido a sumir el Derecho Constitucional finisecular en el caos y la contradicción. Apreciación ésta que, entendemos, no ha de ser muy difícil de

69 Cfr. H. Kelsen, Teoría General del Derecho y del Estado, cit., pág. 185. P. De VegA, "Jurisdicción constitucional...", cit., págs. 94 y, sobre todo, 96; "Constitución y Democracia", cit., pág. 77; La reforma constitucional..., cit., pág. 70. Incide también en la inescindible relación entre Constitución rígida y control de constitucionalidad, P. CRUz VILlalón, La formación..., cit., pág. 342

70 Cfr. P. De Vega, "Mundialización y Derecho Constitucional:...”, cit., págs. 36 y ss. 
entender y comprender. Sobre todo, si se toma en consideración que se trata de un Derecho Constitucional en el que, abandonado el principio democrático y eliminado el concepto de Pouvoir Constituant, por un lado, y ajeno al contenido ideológico real de la Libertad, por otro, los Tribunales Constitucionales han podido ser elevados a la condición no del aquel legislador negativo del hablaba Kelsen, ni siquiera a la de aquel órgano del Estado al que, en tanto en cuanto contribuía al desarrollo del Texto Constitucional con su interpretación de éste, Charles Durand le atribuía la naturaleza de ser un Poder Constituyente secundario ${ }^{71}$, sino, por el contrario, a la de ser el único y auténtico soberano en el Estado. A ello responden, en efecto, las concepciones actuales que, aunque de modo seguramente inconsciente, convierten al Tribunal Constitucional en un poder político-existencial que, por él mismo, y no por aplicar la Constitución, garantiza los fundamentos de orden de la Comunidad Política, atribuye y delimita las facultades competenciales del resto de los poderes constituidos, y, finalmente, marca los límites de las normas jurídicas ordinarias.

Lo que, de verdad, nos interesa destacar es que fue en el marco de la etapa weimariana donde, como respuesta a la nueva realidad política, se crearon o, como mínimo, se pusieron en funcionamiento todos los instrumentos jurídicos que, a la postre, permitieron a los Códigos Constitucionales desplegar toda su dimensión jurídica y su proyección normativa. Entre ellas, los Tribunales Constitucionales. El Profesor De Vega, con meridiana claridad y total contundencia, ha puesto de manifiesto la importancia y relevancia que una tal solución reviste. En este sentido, escribe el Maestro que «Como gran aportación histórica de este nuevo constitucionalismo aparece la creación de los Tribunales Constitucionales cuya función principal, [...], no es otra que la defensa y garantía de los dos grandes pilares - [...] - en los que se asienta la estructura del Estado Constitucional Moderno. Velar por la constitucionalidad de las leyes, garantizar correctamente la interpretación de la Constitución y, en última instancia, procurar que la Constitución se cumpla, no significa otra cosa que preservar y defender la voluntad de ese poder soberano del pueblo que, [...], una vez ejercitada su obra como poder constituyente, desaparece de la escena política. Cuando se dice que el Tribunal Constitucional es el defensor de la Constitución, lo que realmente se está expresando es que es el guardián de la voluntad de la voluntad constituyente del pueblo" ${ }^{72}$.

Sea de ello lo que sea, importa señalar que todas estas transformaciones jurídicas, que encuentran su origen en cambios que, de manera fundamental y básica, son de carácter político, no pasaron desapercibidas para los estudiosos del Estado, la Política y el Derecho. Ni siquiera pudieron aquéllas ser ignoradas por los autores del positivismo jurídico. Y ello, a pesar de su gran

71 Cfr. Ch. Durand, Les États Fédéraux. Étude de Droit Constitutionnel Positif, París, 1930, págs. 96-109 y 241.

72 P. De Vega, "Prólogo" a A. DE CABo (ed.), La Constitución española de 27 de diciembre de 1978, cit., pág. XXI. 
empeño en construir una doctrina constitucional totalmente objetiva, científica y pura desde la antidialéctica, e imposible, pretensión de actuar con la más absoluta, tajante y definitiva neutralidad ideológica, por un lado, y sobre la acientífica separación entre la verdad jurídica y teórica y la verdad político-histórica y práctica, por otro. Sus construcciones, en efecto, y como nadie está en condiciones de negar y desmentir, resultaron decisivas para el reconocimiento dogmático del valor jurídico de los Textos Constitucionales.

De cualquier forma, fue Hans Kelsen ${ }^{73}$ quien desempeñó un papel central en este proceso. Como está generalmente aceptado, corresponde a la obra del insigne jurista austriaco el gran mérito de haber dotado de su verdadero sentido y magnitud a las afirmaciones que, desde antiguo $-\mathrm{y}$ como hemos visto-, venía haciendo el positivismo jurídico formalista de los Códigos Fundamentales como normas jurídicas cuyos preceptos, precisamente por esta condición, habrían de gozar de una auténtica fuerza jurídica obligatoria y vinculante.

Ocurre, sin embargo, y como a nadie puede, creemos, ocultársele, que si Kelsen, —como fundador del llamado "grupo de Viena" y más sobresaliente representante del positivismo jurídico en la Teoría Constitucional de Weimar, del que, no sin alguna razón, Heller pudo decir que era "el consecuente ejecutor testamentario" de Laband ${ }^{74}$, que "había conducido ad absurdum de modo definitivo el positivismo lógico jurídico en la Teoría del Estado, aplicándolo con gran vigor y profunda agudeza ${ }^{75}$, y que acabó contribuyendo, más que ningún otro, al vaciamiento del contenido material del Estado de Derecho con su radical despersonalización del poder político ${ }^{76}$ - hubiera sido totalmente coherente con el método positivista que le sirvió de fundamento para la redacción de sus celebérrimas "Problemas fundamentales de la Teoría del Derecho del Estado" "7 "Teoría pura del Derecho" "78, "Teoría General del Estado" y "Teoría General del Derecho y del Estado", nunca hubiera podido llegar a esta conclusión. La razón es fácilmente comprensible.

Debemos, a este respecto, a Heller ${ }^{79}$ la observación de que, siguiendo las enseñanzas de Hermann Cohen, y de un modo muy particular sus afirmaciones de que la Ciencia del Derecho es la matemática de las ciencias del espí-

73 Sobre la construcción de Kelsen y su crítica, cfr., en general, y por todos, P. LuCAS Verdú, "La teoría escalonada del ordenamiento jurídico como hipótesis cultural, comparada con la tesis de Paul Schrecker sobre la "estructura de la civilización"», Revista de Estudios Políticos, n. 66 (1989), págs. 7-65; "El orden normativista puro (Supuestos culturales y políticos en la obra de Hans Kelsen)", Revista de Estudios Políticos, n. ${ }^{\circ} 68$ (1990), págs. 1-93.

74 H. Heller, La soberanía..., cit., pág. 90; vid., también, págs. 149 y ss.

75 H. Heller, "La crisi..., cit., pág. 52.

76 Sobre este particular, cfr. H. Heller, "Europa y el fascismo", cit., págs. 27 y ss., especialmente págs. 30-31.

77 H. KELSEN, Hauptprobleme der Staatsrechtslebre, enweickel aus der Lehre von Rechtssat$z e$, Viena, 1911.

78 H. Kelsen, Teoría pura del Derecho. Introducción a la Ciencia del Derecho, Buenos Aires, $1970,9 .^{\mathrm{a}} \mathrm{ed}$.

79 Cfr. H. Heller, "La crisi...”, cit., págs. 50-51; "Osservazioni...”, cit., pág. 390. 
ritu $^{80}$ y que la "Teoría del Estado es necesariamente una Teoría jurídica del Estado. La metódica de la Teoría del Estado se encuentra en la Ciencia jurídi$\mathrm{ca}{ }^{81}$, procedió Kelsen a la reducción del Derecho Constitucional, y su estudio, a una serie de reglas lógico-matemáticas que, a la postre, y por decirlo con las palabras del propio jurista vienés, condujera a la ciencia normativa a convertirse en una "geometría de la totalidad del fenómeno jurídico" ${ }^{82}$. No es, obviamente, éste el momento oportuno para detenernos a precisar si, como el jurista austriaco pretendía, su construcción científica era la culminación del método positivista puro, o si, por el contrario, la misma no logró substraerse a los influjos del Derecho Natural liberal y marxiano, en el sentido de que, como escribe Heller, "Pero no obstante esas referencias al derecho natural, Kelsen pretende ser un positivista puro, lo que le conduce a la afirmación de la posibilidad del estado de derecho, independientemente de su contenido ético, político y social de que se le dote y a la concepción del derecho como una forma susceptible de recibir cualquier contenido. Sus especulaciones, en la medida en que no constituyen, [...], las bases de un anarquismo disfrazado, no pueden negar su entroncamiento con el pensamiento democrático-liberal. Ocasionalmente emerge también en Kelsen la noción de ordre natural impersonal como el ideal jurídico por realizar: [...]. En su lucha en contra del dogma de la soberanía, la Teoría pura del Derecho se presenta revestida de un particular atractivo [...], enlazándose con el derecho natural marxista, 83 .

Lo que realmente nos interesa, ahora, es tan sólo tratar de poner de relieve las consecuencias que se derivan de una tal concepción. Consecuencias que, según nuestro modesto entender, resultan tan evidentes como gravosas para el cabal y ponderado entendimiento del Derecho Constitucional, y, desde luego, y aunque pueda parecer paradójico, para la adecuada y debida comprensión de la dimensión jurídica y proyección normativa de la Constitución. En este sentido, nos encontramos con que la aceptación de las tesis de Cohen, obligó a Kelsen ${ }^{84}$ a admitir, de una u otra forma, la radical distinción, propuesta ya por el primer positivismo jurídico formalista, entre lo político y lo jurídico, y, de una manera muy concreta, entre la sociología y la política, por un lado, y la jurisprudencia, por otro.

Muchas fueron las críticas que a esta postura metodológica se hicieron por parte de la que, como dice el Maestro De Vega ${ }^{85}$, se presenta como la mejor Teoría del Estado y de la Constitución, que es la que, en el marco del rico, fecundo y lúcido contexto intelectual de la época weimariana, comenzaron al elaborar Hermann Heller y Rudolf Smend, y de la que, por lo demás, se derivan las más valiosas e importantes concepciones del Derecho

80 Cfr. H. CoHen, Ethik des reinen Willens, Berlín, 1921, pág. 67.

81 H. CoHen, Ethik..., cit., pág. 64.

82 H. Kelsen, Hauptprobleme..., cit., pág. 93.

83 H. Heller, La soberanía ..., cit., pág. 91.

84 Cfr., p. ej., H. KeLSEn, Der soziologische und der jurische Staatsbegriff, Tubinga, 1922.

85 Cfr. P. De Vega, "Mundialización y Derecho Constitucional:...”, cit., págs. 47-54. 
Constitucional del presente, como son las que, por ejemplo, von Bäumlin ${ }^{86}$, Hesse $^{87}$, Krüger, Müller ${ }^{88}$, Schneider ${ }^{89}$, e, incluso, las del popperiano Häber$1 \mathrm{e}^{90}$. De todas ellas, aquí nos interesa destacar tan sólo tres, y por las consecuencias prácticas que las mismas tienen y que, de uno u otro modo, nos afectan directamente hoy.

1. $\left.{ }^{a}\right)$ No hace falta ser en extremo perspicaz, ni, tampoco, realizar un gran esfuerzo intelectual, para comprender que cuando Kelsen pretende reducir toda la problemática del Derecho Constitucional a un conjunto de reglas lógico-matemáticas y geométricas, no hace, en realidad, más que repetir aquella pretensión del primer positivismo jurídico formalista, y principalmente la de la Escuela Alemana de Derecho Público, de proceder a la forja de una Teoría Consitucional totalmente objetiva y científica, elaborada al margen de la realidad política, social y económica que la Constitución pretende regular y conducir. Las consecuencias que se derivan de un tal método de estudio son, a nuestro juicio, demasiado evidentes como para necesitar de mayores comentarios. De cualquier modo, fue, en la academia constitucional española, Pedro Cruz quien se encargó de ponerlas de manifiesto cuando, como sabemos, ironizaba, en 1981, sobre las dificultades que había de encontrar aquel imaginario curioso jurista persa empeñado en conocer la estructura territorial del Estado español atendiendo, única y exclusivamente, al Texto de 27 de diciembre de 1978, en el que no existe ninguna mención literal al modelo de Estado.

A la pretensión del positivismo jurídico se opuso, de manera clara y radical, el positivismo sociológico tanto en su versión del positivismo sociológico realista de León Duguit ${ }^{91}$, como en el institucionalista de Maurice Hau-

86 R. von Bäumlim, Die rechtsstaatsliche Demokratie. Eine Unterssuchung der gegenseittigen Beziehungen von Demokratie un Rechtsstaat, Zurcih, 1954; Lebendige oder gebändigte Demokratie?, Basilea, 1978.

87 K. Hesse, "El Estado Federal Unitario" (1962), Revista de Derecho Constitucional Europeo, n. ${ }^{\circ} 6$ (2006), págs. 425-456; "Bundesstaatsreform und Grezen der Verfassungsänderung", Archiv des öffentlichen Rechts, Bd. 98 (1973), págs. 1-52.

88 F. MÜLLER, Normstruktur und Normativität. Zum Verhaältuis von Recht und Wirklchkeit in der Juristischen Hermeneutik, entwicklet an fraggen der Verfassungsinterpretation, Berlín, 1966; Normaberrich von Einzelgrundrechten in de Rechtsprechung des Bundesverfassungsgerichts, Berlín, 1968; "Tesis acerca de la estructura de las normas jurídicas", Revista Española de Derecho Constitucional, n. ${ }^{\circ} 27$ (1989), págs. 111-126.

89 H.-P. SCHNEIDER, Richtterrecht. Gresetzrecht und Verfassungsrecht, Francfort/M, 1969; Die Parlamentariche Opposition im Verfassungsrecht der Bundesrepublik Deutschland, Francfort/M, 1974, 2 vols.

90 P. HäBERLE, Retos del Estado Constitucional, Oñati, 1996; Libertad, igualdad, fraternidad. 1789 como historia, actualidad y futuro del Estado Constitucional, Madrid, 1998; El Estado Constitucional, México, 2000; Pluralismo y Constitución. Estudios de Teoría Constitucional de la sociedad abierta, Madrid, 2002; La garantía del contenido esencial de los derechos fundamentales en la Ley Fundamental. Una contribución a la concepción institucional de los derechos fundamentales y a la teoría de la reserva de ley, Madrid, 2003.

91 L. Duguit, La separación de poderes y la Asamblea Nacional de 1789 (1893), Madrid, 1996; Ëtudes de Droit Public: L'État, Le Droit objetive, la Loi positive, París, 19001; Traité de Droit 
riou $^{92}$, y el voluntarista o decisionista, y, en todo caso, claramente antidemocrático, de los Carl Schmitt, Otto Koelreuter, Ernst Forsthoff ${ }^{93}$. Aunque con distintos matices, todos ellos se caracterizaron porque, frente al ensalzamiento y, de una u otra suerte, divinización de la norma jurídica a la que procedía el positivismo jurídico formalista, ellos hacían lo propio con la realidad política, social y económica, en detrimento de la realidad jurídica. Lo que, en último extremo, resultaba igualmente pernicioso para el cabal entendimiento del Derecho Constitucional. Es menester tener en cuenta, en este sentido, que al atender de manera principal, sino exclusiva, a la realidad política, y olvidar la norma concreta, lo que sucede es que, como ha escrito De Vega, los autores del positivismo sociológico "proclamando el valor supremo de la realidad terminaban reduciendo la política a pura decisión, considerando a la normativa constitucional como una apócrifo, injustificado y fantasmagórico sistema reductor de lo político" ${ }^{94}$.

Oponiéndose por igual al positivismo jurídico formalista y al sociológico, expusieron Heller y Smend su visión sobre el Derecho Constitucional, y sobre el método adecuado para su estudio. Punto de partida para ambos autores fue, como ya hemos tenido ocasión de señalar, la idea de que la Constitución no es sólo, y como entendía el positivismo jurídico, norma jurídica, como tampoco, y como defendía el positivismo sociológico, es pura realidad, sino que, por el contrario, aquélla únicamente puede comprenderse como la unión de ambas realidades. Dos son, de forma fundamental, las consecuencias que se derivan de la anterior concepción.

La primera de ellas, se refiere en concreto al método. A saber: Porque la Constitución, como Derecho positivo del Estado, es norma jurídica, pero también realidad política, social y económica (Smend), evidente resulta que el estudio y comprensión del Derecho Constitucional requiere que el constitucionalista atienda por igual a la realidad jurídico-normativa y a la realidad político-social. Lo que, traducido en otros términos, significa que nos encontramos ante una Ciencia que, lejos de ser una construcción lógico-matemática y geométrica de la totalidad del fenómeno jurídico, o una exposición sociológica y política del fenómeno político, se presenta com una ciencia que, sin renunciar a su carácter normativo, lo es también de la realidad. Heller ${ }^{95}$ se encargaría de ponerlo claramente de manifiesto cuando, en su magnífica e inacabada Staatslebre, advierte que el objeto de la Teoría del Estado y del Derecho Constitucional no es, ni, por lo demás, puede ser otro, que la explica-

Constitutionnel, París, 1921, 2. ${ }^{\text {a }}$ ed., 4 vols.; Manuel de Droit Constitutionnel, París, 1923; Soberania y libertad, Madrid, sine data.

92 M. Hauriou, La souveranité nationale, París, 1912; Principios de Derecho Público y Constitucional, Madrid, 1927; Précis de Droit Constitutionnel, París, 1929, 2. ${ }^{\text {a }}$ ed.; Teoria dell'istituzione e delle fondazione, Milán, 1967.

93 E. Fonsthoff, Tratado de Derecho Administrativo, Madrid, 1958; El Estado de la sociedad industrial, Madrid, 1975.

94 P. De Vega, "Mundialización y Derecho Constitucional....”, cit., pág. 32.

95 CFr. H. Heller, Teoría del Estado, cit., págs. 67-68. 
ción jurídica de las relaciones de poder que actualmente existen en la Comunidad Política, averiguar cuál puede ser su evolución y, como deber inexcusable del constitucionalista, tratar de influir con sus formulaciones, - que siempre han de ser críticas ${ }^{96}$ - , en dicha evolución.

La segunda de las consecuencias que han de extraerse de la postura de Heller y Smend, tiene, si así quiere decirse, una dimensión más práctica. La misma se concreta en las reflexiones, partiendo de las observaciones realizadas en su día por Smend, su Maestro, hizo, en 1950, Konrad Hesse en torno a la "Die normative Kraft der Verfassung,", con las que, en último término, acababa oponiéndose por igual tanto al sociologismo de un Lassalle, como al normativismo puro de un Kelsen. De una manera básica, la tesis de Hesse se concreta en lo siguiente: Porque la Constitución es norma y realidad, lo que sucede es que si, como acierta a ver el positivismo jurídico, la fuerza normativa de los Códigos Constitucionales encuentra su origen y fundamento en el propio texto de la Constitución, la verdadera eficacia de aquella acaba, sin embargo, y en cuanto que es realidad, dependiendo no tanto de las prescripciones contenidas en la Ley Constitucional, cuanto del uso y desarrollo que de las mismas hagan las fuerzas políticas que operan en el Estado de que se trate. Con lo que, como ha de ser para todos obvio, la "Constitución formal" acaba transformándose en la "Constitución real" (Lassalle) o "Constitución en sentido material" (Mortati).

2. $\left.{ }^{a}\right)$ Fue, en sengundo lugar, también críticada la metodología kelseniana en cuanto que, por mucho que el vienés se empeñase en lo contrario ${ }^{98}$, entendían Heller y Smend que conducía a la formulación de un Derecho Constitucional ajeno a las categorías "espacio" y "tiempo". Crítica que, entendemos, no ha de resultar muy difícil de comprender.

Es menester, en este sentido, tomar en consideración que al pretender reducir toda la problemática del Derecho Constitucional a un conjunto de reglas lógico-matemáticas y geométricas, el Kelsen postivista formalista puro acaba, de una u otra suerte, participando de aquella concepción del Estado y del Derecho como realidades eternas, absolutas, invariables e intemporales que, como denunció Heller ${ }^{99}$, había propuesto el primer positivismo jurídico formalista, y que, en última instancia, les condujo a la elaboración de aquellas grandes Teorías Generales del Estado y del Derecho Constitucional en las que, haciendo, como sabemos, suyo el lema del idealismo, se procedía a formular unos modelos ideales y míticos a los que debía adecuarse la realidad estatal. Y es que, como a nadie puede ocultársele, al aceptar Kelsen la visión de Cohen, lo que está diciendo no es más que las soluciones jurídico-constitucionales de hoy, han de resultar, en cuanto que

96 Cfr., en este sentido, P. DE VEGA, "En torno al concepto...; cit., págs. 702-703.

97 Cfr. K. Hesse, "La fuerza normativa de la Constitución" (1959), en el vol. Escritos de Derecho Constitucional (Selección), cit., págs. 61-84.

98 Cfr., a este respecto, H. Kelsen, El Estado como integración..., cit., págs. 21 y ss.

99 Cfr. H. Heller, Teoría del Estado, cit., pág. 19. 
fruto de un razonamiento lógico-matemático, geométrico y abstracto, válidas en todo momento y lugar.

Las consecuencias prácticas que se derivan de una tal comprensión del Derecho Constitucional, se nos antojan lo suficientemente claras y meridianas como para precisar de mayores comentarios teóricos. Lo que, en realidad, nos interesa es destacar que, como muy bien comprendieron Heller y Smend en su crítica al método del jurista austriaco, aquéllas son tan evidentes y perniciosas para la consolidación y desarrollo del naciente Estado Constitucional democrático y social, como lo fueron, en su día, las del primer positivismo jurídico formalista respecto del viejo Estado Constitucional liberal. De cualquier forma, la dinámica jurídico-política de la España actual nos ofrece un magnífico campo de prueba para comprobar lo acertado de la crítica que los juristas alemanes habían hecho a Kelsen.

A este respecto, ha de tenerse en cuenta que ha sido, justamente, esta atemporalidad con la que el positivismo jurídico formalista, - tanto el de la Escuela Alemana de Derecho Público de los von Gerber, Laband y Jellinek, como el del Kelsen de la teoría jurídica pura-, revestía sus construcciones científicas en el mundo del Estado, la Política y el Derecho la que, en última instancia, ha servido de base a los juristas, intelectuales, historiadores y artistas al servicio del nacionalismo conservador vasco para elaborar una serie de argumentos tendentes a que el P.N.V. pueda, partiendo de un dato histórico-político objetivo y cierto, y analizándolo de acuerdo con los criterios legitimadores y vertebradotes del Estado actual, proceder a poner en cuestión la legitimidad de la unidad del Estado español. Su argumentación no puede ser más contundente. Despreciando la observación hecha, por ejemplo, por Tomás y Valiente de que «España es una realidad histórica, un producto de la historia, construida por los hombres que sucesivamente ha vivido en su actual territorio. [... y que] ha habido largos períodos durante la dominación romana o entre 1580 y 1640 en que toda la Península ibérica ha constituido una unidad política ${ }^{100}$, preferirá el nacionalismo conservador vasco centrarse en aquellos otros momentos en que dicha unidad política no existía, y en los medios utilizados para lograrla y, con ello, dar paso al nacimiento histórico del Estado español. En este punto, llegarán, incluso, alguno de los juristas, historiadores y artistas que aconsejan al partido conservador vasco a aceptar, — siempre en lo que no afecta a la vigencia mítica del Derecho foral vasco y a la, no menos mítica, existencia de una unidad o sociedad política vasca-, que no le falta razón a Tomás y Valiente cuando afirma que "A lo largo de los siglos XI y XII los tres territorios [Álava, Guipúzcoa y Vizcaya] pertenecieron, en oscilación propia de tierras fronterizas, a Navarra o a Castilla. Desde el siglo xIII, sin interrupción ni crisis alguna, fueron territorios incardinados dentro de la Corona de Castilla, diferenciados entre sí y dotados de regímenes jurídicos propios si bien muy castellanizados ${ }^{101}$.

100 F. TOMÁs y VALIENTE, "Raíces y paradojas de una conciencia colectiva", en el vol. Escritos sobre y desde el Tribunal Constitucional, Madrid, 1993, pág. 193.

101 F. Tomás y Valiente, "Raíces y paradojas...", cit., pág. 200. 
No debería ser necesario aclarar que, si se acepta el aserto de Tomás y Valiente, no puede existir la menor duda sobre el hecho de que la incardinación de los territorios vascos a la Corona de Castilla, o, si se prefiere dar por válida la irreal visión castellana y castellanizante de la Historia puesta en marcha por la generación del $98^{102}$, a España, no es el resultado de una imposición realizada a golpe de espada, sino el de una decisión libremente adoptada por los distintos señores vascos y el rey de Castilla o de Navarra. No obstante lo anterior, el nacionalismo conservador vasco se mostrará especialmente firme a la hora de negar la legitimidad de ese proceso, de suerte tal que la unidad no puede vincular al Pueblo vasco y, en consecuencia, le autoriza a ejercer en cualquier momento el derecho de secesión. Que ello sea así, se explica, siempre según el discurso del nacionalismo conservador vasco, por cuanto que aquel acuerdo de unidad fue adoptado por los señores vascos y el rey, sin tomar en consideración la verdadera voluntad del Pueblo vasco, entendido como un ente metafísico, abstracto y atemporal al que pertenecían las generaciones pasadas, las presentes y las futuras.

Que el Pueblo vasco no participó en el proceso de decisión sobre la integración, es algo que nadie niega, ni podría discutir. Debería quedar igualmente claro que ni el Pueblo navarro, ni el castellano, - por cierto, el primero de los Pueblos españoles que, como respuesta inmediata a su implicación mayoritaria en la revolución comunera, conoció la fuerza de la espada del absolutismo, y el primero que se vio despojado de su Derecho propio en beneficio de la monarquía católica-, jugaron un papel relevante en aquellos contratos feudales entre los distintos señores territoriales vascos y el rey navarro o el castellano. La original unidad de España, de esta suerte, y como, entre otros, ha puesto de relieve Pi i Margall103, se llevó a cabo no como el fruto de la voluntad de los individuos de los diversos territorios que, como el helleriano "Pueblo como diversidad", decide libremente erigir sobre ellos el "Pueblo como unidad" y, en definitiva, crear el Estado, sino, por el contrario, como el resultado de la voluntad única y exclusiva, de sus gobernantes en el medievo.

Ahora bien, que esto sea así, no le resta, ni mucho menos, legitimidad a aquella primigenia unidad. Y ello por la sencillísima razón de que los sucesos políticos históricos y pretéritos han de ser enjuiciados, no desde los criterios legitimadores y vertebradores del Estado actual, sino desde los que operaban en aquel momento. Observación ésta que, en definitiva, me ratifica en lo que, en 1995, escribí a este respecto: "Ahora bien, no puede olvidarse el momento en que se crearon las Coronas de Aragón y de Castilla: la Edad Media. De esta suerte, lo que sucede es que las mismas resultan legítimas en tanto en cuanto que la decisión sobre la integración la adoptaron los únicos que, en aquel momento, aparecían legitimados para decidir sobre el gobierno de aquellos territorios. Me refiero, claro está, a los gobernantes ${ }^{104}$.

102 Cfr., en este sentido, E. Tierno Galván, "Costa y el regeneracionismo”, cit., pág. 429.

103 Cfr. F. Pi i Margall, Las Nacionalidades (1877), Madrid, 1986, págs. 198 y ss.

104 J. Ruipérez, Constitución y autodeterminación, cit., pág. 106. 
En idéntico despropósito se incurre, según nuestro parecer, cuando, apelando a esa atemporalidad de las construcciones dogmáticas del positivismo jurídico formalista, se pretenden articular soluciones a los problemas jurídicos y políticos de hoy desde los criterios legitimadores de épocas pasadas. Esto es, y como he tenido ocasión de denunciar en algún otro lugar ${ }^{105}$, lo que realmente sucede con el llamado "Plan Ibarretxe". En efecto, lo que, dejando al margen toda la palabrería retórica y demagógica sobre el referéndum, realmente esconde éste no es más que el intento del P.N.V. de, amparado por el aparato conceptual, — pseudo-científico-, que al efecto le proporciona el más conspicuo mentor del principio monárquico en la España actual, resucitar los esquemas políticos medievales, y, de esta suerte, forzar una situación en la que el Gobierno peneuvista, como señor del territorio de Euzkadi, y el rey, como soberano y dueño del destino de España, acuerden contractualmente el status que va a corresponder al País Vasco en el marco del Estado español.

A la vista de las inconsecuencias a que conducía el método del positivismo jurídico formalista, y que nosotros hemos ejemplificado con la actual dinámica política española, nada de extraño tiene que Heller y Smend se rebelasen contra él. Y lo harían, proponiendo que el estudio del Estado, la Política y el Derecho debía recuperar las fundamentales categorías del espacio y del tiempo. Siendo, sin duda alguna, esta proposición una de las más valiosas e importantes aportaciones de su Teoría de la Constitución. En este sentido, debemos al Maestro De Vega la acertada observación de que tanto Heller como Smend comprendieron perfectamente la «necesidad de integrar los elementos fácticos y normativos, [...], en un sistema unitario [...]. Lo que significa que [...], el Derecho Constitucional rescataba las categorías de espacio y tiempo, y que adquiría dimensiones concretas e históricas evidentes. [...]. Pero significa, a su vez, que el Derecho Constitucional, como conjunto normativo que se involucra en la realidad social y política concretas, no tenía por qué renunciar a dar sentido histórico y a hacer valer sus proposiciones normativas. Al considerar que los valores, principios, contenidos y objetivos establecidos en las normas sólo pueden explicarse cuando responden a los propios valores y principios que conforman la realidad social, se abría el camino para la confrontación entre normatividad jurídica y realidad política pudiera empezar a resolverse ${ }^{106}$.

3. ${ }^{a}$ La última de las críticas que nos interesa destacar, se refiere al cómo ha de estudiarse la problemática constitucional. En este sentido, nos encontramos con que, al reducir todo el Derecho Constitucional a un conjunto de reglas lógico-matemáticas y geométricas, entenderá Kelsen que el mundo jurídico empieza y acaba en las normas del Derecho positivo. De esta suerte, nos encontramos con que, según se desprende del método jurídico puro propugnado por el austriaco, el constitucionalista, en su labor de llevar a cabo

105 Cfr., a este respecto, J. RuIPÉREZ, “Sobre el derecho de autodeterminación”, cit., págs. 365-366 y ss.

106 P. De VeGA, "El tránsito...", cit., pág. 84. 
el análisis de los problemas reales que se plantean en el Estado y la de proceder, - que es, en realidad, la función que les cumple a los Profesores de Teoría del Estado y del Derecho Constitucional (Heller ${ }^{107}$ _- a la tarea de encontrar y proponer soluciones a los mismos, no precisa más que de las normas contenidas en la Constitución. Todo lo más, y dando paso al positivismo jurídico jurisprudencial, el constitucionalista habría de tomar en consideración la interpretación que de aquellas normas realiza el juez constitucional.

A esta tesis se opondría, y de un modo harto contundente, Heller. En efecto, el que, para nosotros, fue el más lúcido, válido, capaz y coherente de los juristas y polítólogos del período entre guerras, afirmará que "TODO PROBLEMA JURÍDICO, SIN EXCEPCIÓN, TIENE SUS RAÍCES, DE un lado, en la sociología y del otro, mirando hacia arriba, en la esfera de lo ético-político. Por tanto, los problemas jurídicos no solamente pueden ser estudiados desde los puntos de vista causal y normativo, sino que, además, exige que se efectúe ese doble estudio" ${ }^{108}$. Lo que, traducido en otros términos, significa que si el constitucionalista ha de tomar en consideración, de forma necesaria e irrenunciable, los preceptos constitucionales positivos y la jurisprudencia, no puede en modo alguno prescindir de los conocimientos de otras ciencias no jurídicas (Teoría Política, Ciencia Política, Filosofía del Estado, Historía, etc.) que, en última instancia, le permitirán comprender los verdaderos motivos por los que aquellas normas se positivizaron, y las auténticas causas de que se haya materializado el problema jurídico concreto.

Sea de ello lo que sea, lo que nos interesa es que, ajeno a estas y a otras críticas que sus coetáneos le hacían, o incluso reaccionando violentamente ante ellas, procedió Kelsen a la elaboración de su Teoría jurídica pura del Derecho Constitucional y del Estado. Y que es desde ésta desde donde, en primer lugar, y como algo ineludible para la determinación del valor jurídico de la Constitución, el ilustre jurista vienés se enfrentó a la problemática de la soberanía.

En este sentido, nos encontramos con que, sentada por Kelsen la contraposición entre sociología/política y la jurisprudencia, lo primero que, a la hora de abordar el problema de la soberanía, hizo el más insigne y famoso miembro del "Grupo de Viena", fue reducir toda la vida del Estado, — comprendido al margen de su dimensión política, social y económica-, a meras relaciones jurídicas. Lo que permite al Profesor austriaco desarrollar la concepción de la despersonalización del poder político, que había sido enunciada por Hugo Krabbe al decir que "En nuestra época, ya no vivimos bajo el dominio de personas, sean naturales o jurídicas, sino bajo el dominio de las normas" ${ }^{109}$, y llevarla hasta sus últimas consecuencias.

No es éste el momento oportuno para detenernos a precisar las consecuencias políticas que se derivaron en el período weimariano de esta absoluta

107 Cfr. H. Heller, Teoría del Estado, cit., pág. 42.

108 H. Heller, La soberanía ..., cit., pág. 111.

109 H. KrabBe, Die moderne Staatslehre, Haag, 1919, pág. 81. 


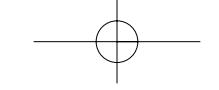

despersonalización del poder político. Aunque, en todo caso, no está de más recordar que las mismas, como denunció ya Heller ${ }^{110}$, resultaron en extremo peligrosas y nocivas para la Democracia y el Estado Constitucional en tanto en cuanto, como de algún modo ha sido ya indicado, tal concepción tuvo una especial atracción para los totalitarismos fascistas.

Lo que realmente nos interesa es que, desde los esquemas conceptuales anteriores, la problemática de la soberanía resulta meridiana para Kelsen. Aquello que llamamos soberanía, no es, en rigor, más que la obligación de respetar y obedecer el Derecho. Así lo sentenciará de manera categórica: «la soberanía del Estado [escribirá el vienés] significa que el orden jurídico estatal es supremo, comprendiendo todos los restantes órdenes como órdenes parciales, determinando el ámbito de validez de todos ellos sin ser a su vez determinado por ningún orden superior " ${ }^{111}$. De ahí se deriva, justamente, su conocida afirmación de que en el Estado Constitucional no cabe más soberanía que la de la Constitución y el Derecho.

Ocurre, sin embargo, que habiendo no sólo aceptado la doctrina de la "Stufenbautheorie" elaborada por su discípulo Adolf Merkl ${ }^{112}$, sino elevado a al condición de la más valiosa aportación a la Ciencia del Derecho ${ }^{113}$ y viéndose, en consecuencia, obligado Kelsen a formular su teoría de la Ley Fundamental $^{114}$, la anterior conclusión se desvanece en el marco de la concepción lógico-matemática de la Teoría del Estado kelseniana. Desde ésta, en efecto, el único corolario posible es que en el Estado no cabe ninguna soberanía. Ni siquiera, y esto es lo importante, la de la Constitución. La razón es fácilmente comprensible. La aplicación de la lógica de la Stufenbautheorie al Derecho Constitucional, lleva a Kelsen a afirmar que la Constitución, que, en cuanto norma que establece el procedimiento para la creación del resto del Derecho y señala el órgano competente para su emanación, es la fuente de validez del Derecho del Estado, necesita ella misma, y en la medida en que es una norma jurídica, extraer su propia validez y fuerza normativa vinculante de una norma jurídica superior. Esta última, en principio, habrá de identificarse con aquella "primera Constitución [del Estado] más allá de la cual no es posible remontarse " ${ }^{15}$ y que, en último extremo, se determinaría por la verificación de alguna situación revolucionaria ${ }^{116}$ que comporte un cambio en lo que Guglielmo Ferrero ${ }^{117}$ llama "principio de legitimidad".

Ahora bien, ocurre que esta primera Constitución del Estado requiere a su vez, y dada su condición de norma jurídica, de una norma superior que le

110 Cfr. H. Heller, "Europa y el fascismo", cit., págs. 31 y ss.

111 H. Kelsen, Teoría General del Estado, cit., pág. 142.

112 A. MerkL, "Die Lehre von der Rechtskraf. Entwickelt aus dem Rechtsbegriff", en Wiener Staatsewissenchaftliche, 15, bd. 2 Helft, Leipzig, 1923, págs. 81 y ss.

113 Cfr. H. Kelsen, Teoría General del Estado, cit., p. 305.

114 Cfr. H. Kelsen, Teoría pura..., cit., págs. 40, 137-138, 139, 143 y 145-146.

115 H. Kelsen, Teoría pura..., cit., pág. 40.

116 Cfr. H. Kelsen, Teoría pura ..., cit., págs. 140-141.

117 Cfr. G. Ferrero, El poder..., cit., pág. 30. 
otorgue su fuerza jurídica obligatoria y vinculante. Y ésta, para Kelsen ${ }^{118}$, y desde el monismo jurídico radical, sólo puede ser el Derecho Internacional. De esta suerte, nos encontramos con que no hay ya una soberanía del Estado, ni siquiera la del Derecho estatal. La soberanía, como obligación de respetar y obedecer el ordenamiento jurídico, corresponderá singular y exclusivamente al Derecho Internacional.

No fueron, ni mucho menos, Kelsen y los demás autores del monismo radical los únicos juristas que, en el marco de la Teoría de la Constitución de Weimar, atribuyeron al Derecho Internacional la condición de Ley Suprema y Ley Fundamental del ordenamiento jurídico. En efecto, de esta misma idea participaba también el llamado monismo jurídico moderado, al que se adscribían, por ejemplo, y sin ánimo de ser exhaustivos, dos de los más aventajados discípulos del ilustre Profesor austriaco, como eran Verdross ${ }^{119}$ y Kunz $^{120}$. Éstos justificarían la supremacía del Derecho Internacional sobre el Derecho Constitucional con una fundamentación bien distinta a la utilizada por su Maestro.

En este sentido, nos encontramos con que, partiendo de la más que discutible equiparación de la soberanía con el principio de la KompetenzKompetenz, entendieron tanto Verdross como Kunz que, en el mundo actual, la soberanía solamente puede corresponder a la Comunidad Internacional. Aquí reside, de manera concreta, la razón de que el Derecho Internacional pueda, y deba, imponerse al Derecho Constitucional. Su construcción, por lo demás, no es sorprendente y, de cualquier modo, resulta coherente desde el punto de vista de la lógica jurídica. Al fin y al cabo, ha de tomarse en consideración que, al afirmar a la Comunidad Internacional, en cuanto que titular de la más amplia competencia sobre la competencia posible, como sujeto soberano que, por ser tal, puede imponer su voluntad a todos, lo que el monismo jurídico moderado hace es solventar el problema de que, como de modo certero ha observado Heller ${ }^{121}$, el Derecho no es más que un conjunto de reglas que se imponen en la medida en que existe un poder soberano que les otorga esa validez y les confiere su carácter obligatorio y vinculante.

Ahora bien, es necesario advertir, de forma inmediata, que a lo que en realidad conduce el monismo jurídico moderado no es, como ellos querían, a la demostración de la supremacía del Derecho Internacional sobre el Derecho interno de los diferentes Estados, sino, muy al contrario, a la imposibilidad de seguir planteando la confrontación entre el Derecho Internacional y el Derecho Constitucional. Afirmación ésta que resulta difícilmente cuestionable, y que, por lo demás, se hace especialmente patente desde los esquemas conceptuales y metodológicos del antiformalismo helleriano.

118 Cfr. H. Kelsen, Teoría pura..., cit., págs. 190-191.

119 Cfr. A. Verdross, Die Verfassung des Völkerrechtsgemeinschaft, Viena, 1926; "Le fundament du Droit Internationel", Recuil des Cours de l'Académie de Droit Internationel de Le Haye, 1927, t. I, págs. 269 y ss.; Völkerrecht, Viena, 1964, 5. a ed.

120 Cfr. J. L. Kunz, Die Staatenverbindungen, Stuttgart, 1929.

121 Cfr. H. Heller, La soberanía..., cit., págs. 127 y ss., particularmente págs. 141-142. 
Es menester tomar en consideración, en este sentido, que la única manera posible de concebir a la Comunidad Internacional como titular de la soberanía, es la de afirmar que el proceso altusiano de creación del cuerpo político, y, con ello, de determinación del titular del ejercicio de la soberanía, ha conocido un paso más: la celebración de un nuevo pacto social entre los diversos Estados hasta entonces soberanos e independientes, en virtud del cual éstos, en su consideración de "Pueblo como diversidad", deciden libremente erigirse en "Pueblo como unidad", procediendo, en consecuencia, al establecimiento sobre ellos de un cuerpo político único, superior y englobador de todos sus miembros, y en el que los viejos Estados se integrarían y disolverían. Con ello, obvio es, la Comunidad Internacional se transformaría en un único Estado, como "unidad organizada de decisión y acción política" ${ }^{122}$, a escala planetaria.

El resultado de todo ello, no puede ser más evidente. Las normas jurídicas emanadas por la Comunidad Internacional/nuevo Estado mundial, no pueden ser ya consideradas como integrantes de un Derecho Internacional que, por su propia esencia, y, - como recientemente recordaba el Maestro De Vega $^{123}$ - al menos desde Grocio $^{124}$, requiere la concurrencia de dos o más Estados soberanos e independientes. De esta suerte, nos encontramos con que, como con meridiana claridad vio Heller, la conversión de la Comunidad Internacional en una "unidad decisoria planetaria, universal y efectiva, transformaría al derecho internacional en derecho estatal " ${ }^{125}$, es decir, en auténtico Derecho Constitucional cuya fuerza obligatoria y vinculante se deriva de su condición de ser la obra del soberano en el Estado.

Bien distinta tanto de la construcción del monismo jurídico moderado, como de la elaborada por Heller, es la posición de Kelsen. En efecto, para el Maestro austriaco, la supremacía del Derecho Internacional no se deriva, ni mucho menos, de la naturaleza soberana del sujeto del que aquél emana, como afirmaba el monismo jurídico moderado, ni, tampoco, de su inevitable conversión en auténtico Derecho Constitucional. Por el contrario, aquélla se deriva del mero hecho de ser una norma válidamente aprobada. Siendo así, y porque la soberanía del Derecho depende del propio sistema jurídico, la categórica conclusión a la que llegará Kelsen sólo puede ser una. A saber: La soberanía, como concepto polémico que es, y que pertenece al ámbito de lo político e ideológico ajeno, por tanto, al mundo jurídico, no existe, y,

122 Sobre esta caracterización de la forma política "Estado", cfr. H. Heller, Teoría del Estado, cit., págs. 246-265.

123 Cfr. P. De VegA, "Mundialización y Derecho Constitucional:...”, cit., págs. 25-26; "El Derecho Comparado desde la Historia", ponencia presentada al I Congreso Internacional sobre Culturas y Sistemas Juridicos Comparadosm Mesa X: "Metodología del Derecho Comparado", organizado por el Instituto de Investigaciones Jurídicas/U.N.A.M., y celebrado en México D.F., los días 9 a 14 de febrero de 2004.

124 Cfr. H. Grocio, "Del Derecho de la guerra y de la paz" (1625), en el vol. Del Derecho de presa. Del Derecho de la guerra y de la paz, Madrid, 1987, "Prolegómenos a los tres libros del Derecho de la guerra y de la paz", $₫ 17$, pág. VII, y Libro I, cap. I, $₫$ XIV, págs. 11 y ss.

125 H. Heller, La soberania ..., cit., pág. 225. 
por ello mismo, "El concepto de soberanía debe suprimirse de manera radical»" ${ }^{126}$.

Esta concepción es la que, como decimos, - $-\mathrm{y}$ lo hacemos con todo el respeto-, habría de incapacitar al Kelsen formalista puro para afirmar el valor jurídico de la Constitución. La misma, de cualquier forma, invita a dar la razón a Heller cuando, en su estudio sobre la soberanía, critica al Profesor austriaco, y le acusa de que al querer ser más jurista que nadie, acaba perdiendo su propio objeto de estudio. Al fin y al cabo, y como, aunque ya se ha indicado, es conveniente recordar e insistir en ello, el Derecho, incluido el Derecho Constitucional, no es más que un conjunto de reglas cuyo valor jurídico obligatorio y vinculante se deriva, única y exclusivamente, del hecho de responder a la voluntad del soberano, y estar respaldado por ésta.

Cabría, en tales circunstancias, pensar que no debería ser de la kelseniana construcción lógico-matemática y geométrica, y que niega la soberanía, del Derecho Constitucional de donde se hubiera debido extraer la idea del valor jurídico de los Códigos Fundamentales. Parecería, en efecto, mucho más lógico que una tal idea hubiese surgido como consecuencia de formulaciones como las de, por ejemplo, Rudolf Smend. Que ello sea así, no ha de resultar muy complicado de entender. Sobre todo, si se toma en consideración que es al ingenio de Smend ${ }^{127}$ al que debemos la, por lo demás acertadísima, afirmación de una de las mayores singularidades del Derecho Constitucional, que le otorga su propia especificidad y que, a la postre, le confiere una cierta autonomía científica respecto del resto de las ramas del ordenamiento jurídico, es la que se refiere a la fuerza normativa, y al carácter jurídico obligatorio y vinculante, de la Constitución. Particularidad que se concreta en que mientras que el resto de las normas jurídicas, las de naturaleza ordinaria que son obra de los poderes constituidos, requieren, siguiendo los esquemas de la Stufenbautheorie, de la existencia de una norma jurídica superior que les atribuya su fuerza normativa vinculante, en el supuesto de la Constitución, en cuanto que norma fundamental obra del Poder Constituyente, ésta se deriva de ella misma.

Ocurre, no obstante, $-\mathrm{y}$ como decimos-, que es de la obra del Maestro vienés de donde, de manera generalizada, se ha hecho derivar la gran conquista del Estado Constitucional democrático y social: la adecuada y cabal ponderación de la dimensión jurídica y la proyección normativa de la Constitución. Lo que, según nuestro modesta opinión, se debe, en buena medida, al hecho de que Kelsen, a diferencia de otos autores del positivismo jurídico formalista del período entre guerras (Preuss, Anschütz, Thoma, etc.), no fue absoluta y totalmente coherente con el método jurídico puro con el que pretendía, y afirmaba, actuar.

No nos referimos, - $\mathrm{O}$, por lo menos, no exclusivamente-, a las contradicciones que existen entre el Kelsen ciudadano y el Kelsen académico, y que

126 H. Kelsen, Das problem der Souveränität un die Theorie des Völkerrecht. Beitrag zu einer Reinen Rechtslebre, Tubinga, 1920, pág. 320.

127 Cfr. R. SmEND, "Constitución...", cit., págs. 140 y ss. 
resultan más que sobresalientes. Piénsese, a este respecto, que, como ciudadano, el más ilustre de los autores del grupo de Viena se encontraba, en el período weimariano, alta e inequívocamente comprometido con el sistema democrático, y que, en consecuencia, su actuación se realiza desde la plena aceptación, y defensa, de las ideas y del principio democrático, y de una manera fundamental del dogma político de la soberanía popular. Por el contrario, - y como hemos visto-, Kelsen como estudioso y teórico del Derecho y del Estado, rechaza, con carácter general, el concepto mismo de soberanía. Pero si esto es así, y lo es, ocurre, por último, - y como con gran sagacidad ha puesto de manifiesto Pedro De Vega ${ }^{128}$ _, que su gran aportación a la Teoría de la Constitución, la problemática de la justicia constitucional y de los Tribunales Constitucionales, dijese lo que dijese él ${ }^{129}$ en su crítica a los planteamientos de Schmitt, sólo puede entenderse, explicarse y justificarse desde la cimentación histórica, social e ideológica del principio democrático, y, además, como mecanismo para articular la defensa de aquel orden político democrático con el que, como ciudadano, estaba definitivamente comprometido.

Lo que realmente nos interesaba aquí es, tan sólo, dejar constancia de que esa falta de coherencia con el método positivista puede ser constatada, incluso, dentro de su quehacer científico. En efecto, es menester tomar en consideración que, como enseña el Maestro De Vega, junto al Kelsen formalista a ultranza al que, no sin razón y, en todo caso, con justicia, criticaban Heller y Smend, existe el Kelsen teórico demócrata de, por ejemplo, "Esencia y valor de la Democracia" o "El problema del parlamentarismo", que, en última instancia, resulta de una mayor utilidad para la correcta y adecuada comprensión del moderno Estado Constitucional, y del que, de cualquier modo, nunca puede prescindirse para lograr una cabal y ponderada comprensión de la obra del ilustre jurista austriaco. Ello es así, por cuanto que "a pesar de la asepsia valorativa, proclamada tan solemnemente por Kelsen, la superación que su obra implicaba de los postulados del viejo positivismo, no dejó por fortuna de tener importantes y significativas consecuencias políticas. Sus embates a la personalidad jurídica del Estado, [...], sirvieron para desmontar los mitos de un Estado de Derecho [...] que bajo la socorrida fórmula de conferir la soberanía al Estado como persona jurídica, había permitido ocultar la más absoluta negación del principio democrático, fundamento y base de toda la construcción del Estado Constitucional» ${ }^{130}$.

Aquí radica, justamente, la mayor, y más importante, diferencia entre los autores de la vieja Escuela Alemana de Derecho Público y Kelsen. Divergencia que, en definitiva, implica los distintos resultados a los que unos y otros llegan. Para empezar, lo que ocurre es que es, de modo fundamental, porque el Profesor austriaco actúa desde el principio democrático y, además, pone todo su ingenio al servicio de la defensa de la Welstanchauung demo-

128 Cfr. P. De Vega, "Supuestos políticos...”, cit., págs. 395-396.

129 Cfr. H. Kelsen, ¿Quién debe ser...?, cit., págs. 5-6, 9 y 81-82, por ejemplo.

130 P. De Vega, "El tránsito...", cit., págs. 73-74. 
crática, que entiende claramente en peligro como consecuencia del ascenso de los totalitarismos en el período entre guerras, por lo que Kelsen puede ser considerado, en tanto que jurista positivista, como el gran teórico del régimen democrático ${ }^{131}$.

La posibilidad de afirmar la dimensión jurídica y la proyección normativa de los Textos Constitucionales queda, en este contexto, francamente expedita. Cierto es que las disquisiciones kelsenianas sobre la Grundnorm vienen a complicar esta afirmación. Y ello por cuanto que las mismas encierran una serie de contradicciones, agudamente denunciadas por Conte ${ }^{132}$, que, a la postre, impedirían concebir a la Constitución como una auténtica Lex Superior, ya que la fuerza jurídica, obligatoria y vinculante de la misma dependería de la existencia de una norma superior que le otorgase ésta. Contradicción de la que, de algún modo, fue ya consciente el propio Kelsen, y que, como hemos visto, trató de superar con su apelación al proceso revolucionario como límite en esa búsqueda hacia atrás del fundamento de la obligatoriedad jurídica del Texto Constitucional. Esta observación, con frecuencia olvidada por quienes se proclaman como los grandes kelsenianos españoles, sería la que permitiera a Alf Ross ${ }^{133}$ superar tas aquellas contradicciones al entender, y afirmar, que, en realidad, la Grundnorm acaba coincidiendo con la Constitución jurídico-positiva que se encuentra vigente en el Estado.

De cualquier modo, lo que nos interesa destacar es que, siendo cierta esta última proposición, nos encontramos con que en el Kelsen formalista a ultranza existe ya, aunque sea de manera implícita, una aceptación de la lógica inherente al dogma político de la soberanía popular. Y es, justamente, esa admisión del principio democrático lo que conduce a Kelsen a considerar que la fuerza normativa del Código Jurídico-Político Fundamental depende, de forma irremediable, de su naturaleza de ser la obra de un Poivoir Constituant que, realizada su labor, desaparece de la escena política en condiciones de normalidad. Es, fundamentalmente, desde este entendimiento, implícito aunque formalmente negado, desde donde cobra sentido pleno su ya conocida afirmación de que en el Estado Constitucional la única soberanía posible es la de la Constitución y el Derecho. Lo que, creemos, no ha de ser muy difícil de comprender, y, de cualquier modo, para nadie, — salvo para los que crean que leer a los clásicos otorga al Derecho Constitucional como ciencia un carácter esotérico y mágico-, ha de resultar un misterio. Lo que ocurre es que es en la medida en que el Texto Constitucional, como obra del Poder Constituyente, es entendido como Ley Suprema, y sólo por ello, por lo que el más ilustre, y, seguramente, más brillante y válido, de los juristas del grupo de Vie-

131 Cfr., en este sentido, y por todos, A. Baldassarre, "Constitución...", cit., págs. 22-25 y 27 , especialmente págs. 23-24; A. LA Pergola, "Premesa” al H. Kelsen, vol. La Giustizia Costituzionale, cit., pág. X; P. De VeGA, "Supuestos políticos...”, cit., pág. 396.

132 Cfr. A. G. CONTE, vOz "Norma fondamentale», en Novissimo Digesto Italiano, Turín, 1965, 3. ${ }^{\text {a }}$ ed., vol. XI, págs. 328-329.

133 Cfr. A. Ross, Teoría de las fuentes del Derecho. Una contribución a la Teoría del Derecho Positivo sobre la base de investigaciones bistórico-dogmáticas, Madrid, 1999, pág. 431. 
na puede, por una parte, configurarlo como la "Constitución material» ${ }^{134}$, es decir, como aquella parte, básica, central y nuclear, del ordenamiento que determina los sujetos y el procedimiento para la creación del resto de las normas jurídicas, y, por otra, teorizar la justicia constitucional, concebida, al menos originariamente y en la obra de Kelsen, como un mecanismo al servicio de la defensa de la Democracia.

Todo lo anterior pone bien de manifiesto que fue, sin duda, el período que coincide con la vigencia de la Constitución de Weimar una etapa especial y particularmente importante para la forja del Derecho Constitucional europeo. Lo fue, en efecto, en el terreno de la práctica, en cuyo haber se encuentra el haber puesto en marcha todos los mecanismos precisos para que el Estado Constitucional adquiriese auténtica entidad y realidad. Pero también lo fue, y es lo que a nosotros interesaba aquí, por la riqueza, profundidad y lucidez de los debates doctrinales que entonces se produjeron. Motivos éstos que justifican sobradamente el interés objetivo que tiene el recordar esta época.

Por mi parte, su recuerdo me ha servido para tratar de satisfacer la invitación del Profesor Alzaga para participar en esta Jornada sobre el estudio del Derecho Constitucional y su posible método. Como decía al inicio de este escrito, no tenía yo la pretensión de proponer ni formular recetas mágicas sobre la metodología de nuestra Ciencia. Trataba, única y exclusivamente, de participar en el encuentro recordando ese magnífico, rico, fecundo y lúcido debate metodológico habido en la Teoría Constitucional de Weimar, y quería, asimismo, intentar poner de manifiesto las consecuencias políticas que se derivaron entonces de la utilización de uno u otro método. Lo que me parecía oportuno en tanto en cuanto son, según mi modesto entender, muchas las enseñanzas que podemos y debemos extraer de aquel debate los constitucionalistas españoles de hoy.

Cierto es que en la actualidad no existe, al menos aparentemente, el riesgo de un nuevo ascenso de los totalitarismos fascistas y comunistas, pero no lo es menos que, con los cada vez más generalizados brotes de violencia irracional y mística, por un lado, y la verificación de un proceso de globalización que, conducido por el neoliberalismo tecnocrático, viene a negar la idea de Democracia y se sitúa al margen de la de la Libertad, por otro, el moderno Estado Constitucional democrático está siendo sometido a unos embates que, como ocurrió en Weimar, ponen en peligro su propia subsistencia. $\mathrm{Y}$ ante esto, termino mis reflexiones de la misma manera como las iniciaba. Esto es, dando la razón a mi dilecto Maestro cuando escribió que "No podemos los constitucionalistas, como aquellos médicos reales, de los que hablaba Quevedo, que ocultaban las enfermedades de los reyes y las convertían en enigmas, ocultar los problemas de la vida constitucional. Sólo de este modo nos veremos liberados de correr igual suerte que la de los galenos de Corte para quienes la enfermedad de los reyes sólo existía dos días: el día 
que eran requeridos para curarles y el día que decretaban su muerte. Triste sería el oficio de constitucionalista si el entusiasmo en los comienzos de un régimen democrático, se transformará luego en silencios culposos de sus problemas, para terminar — como en ocasiones ha ocurrido- constatando con exaltación su final» ${ }^{135}$.

AвSTRACT.-The time known as Constitutional Theory of Weimar has been, unquestionably, one of the richest periods in the construction of the Constitutional Law. In it, really, all the greatest concepts and institutions in wich the modern Constitutional State have been launched. 